$$
\begin{aligned}
& \text { تصور مقتر ح لبر امج إعداد معلم القرن الحادي و العشرين وتتميته مهنياً في }
\end{aligned}
$$

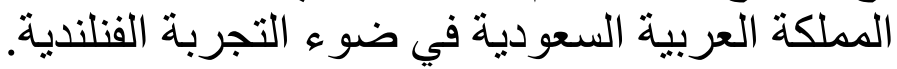

$$
\begin{aligned}
& \text { الأستاذة// منى عائض عطالله المطيري اكتورة/عبير محمد عبد اللطيف العرفج }
\end{aligned}
$$

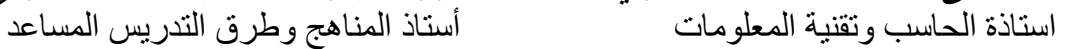

$$
\begin{aligned}
& \text { وز ارة التعليم، الرياض، المملكة العربية السعودية }
\end{aligned}
$$

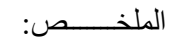

$$
\begin{aligned}
& \text { هدف البحث الحالي إلى وضع تصور مقترح لبرامج اعداد معلم القرن الحادي والعشرين وتنميته مهنياً في المدلكة العربية السعودية }
\end{aligned}
$$

The aim of this research is to develop a proposed vision for programs for the teacher preparation and professional development of the 21st century in the Kingdom of Saudi Arabia by identifying the reality of teacher preparation programs and professional development programs in the Kingdom of Saudi Arabia and comparing it's with the state of Finland to benefit from their experience .The comparative analytical approach has been used, the research found that the reality of teacher preparation programs in Saudi Arabia indicates the poor quality of these programs, the lack of standardized criteria for selecting the best elements, as well as weakness in the professional practices of their outputs, and the professional development programs do not meet the purpose, where the objectives and means marked of weakness and inability to meet the needs of teachers for professional development and lack of the principle of continuous development, While teacher education programs are of quality and select the best elements for enrollment its, as that Professional development programs are diverse and mandatory, meet the needs of the teacher and achieve the principle of continuous development.

The research recommends to development of acceptance policies and the upgrading of highly competitive standards, , and upgrading the teacher preparation programs for the master's degree as a requirement for vocational qualification for new teachers, developing the skills of research teachers and methods of self-learning, paying attention to professional development programs for teachers and development its, diversifying professional development methods, funding its, and forcing teachers to join its and motivate its .

Keywords: teacher, teacher preparation, Professional development, in-service training as 21 st century competencies.

$$
\begin{aligned}
& \text { الاقتصادية والاجتماعية للدولة، فقد وجهت } \\
& \text { الكثير من دول العالم عناية كبيرة لإصلاح } \\
& \text { نظامها التعليمي وتطويره بما يتتاسب مع } \\
& \text { تطورات العصر الحديث. ويعد المعلم من أهم } \\
& \text { مدخلات العملية التعليمية وأكثرها أثراً في تعلم }
\end{aligned}
$$

يشهد العالم في مطلع القرن الحادي والعشرين تطوراً مذهلاً في كافة مناحي الحياة، ولمواكبة هذا التطور لابد من إعداد الفرد إعدادا يمكنه التفاعل مع معطياته، ولما كان التعليم من أكثر المجالات حيويةً وتأثيراً على التتمية 


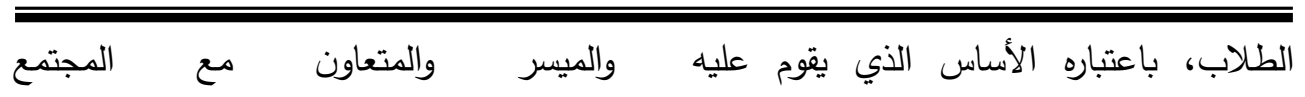

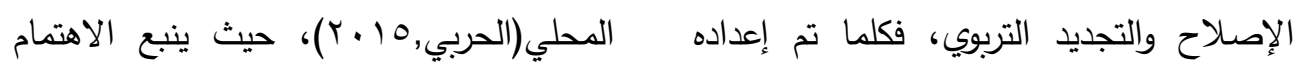

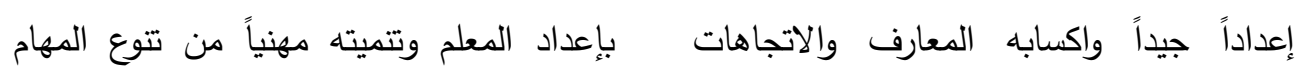
الحديثة في التربية كان ذلك أقدر على إنماء والأدوار التي يؤديها في هذا العصر • وهذا يلزم

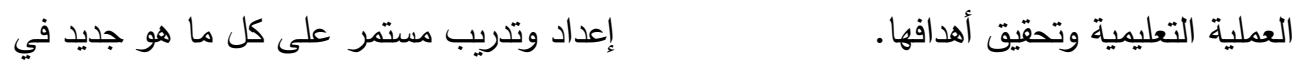
ولقد شغلت قضية إعداد المعلم، مساحة العملية التربوية.

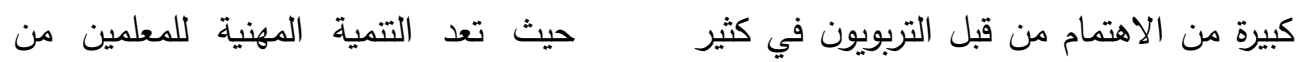

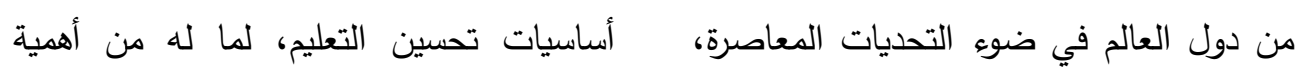

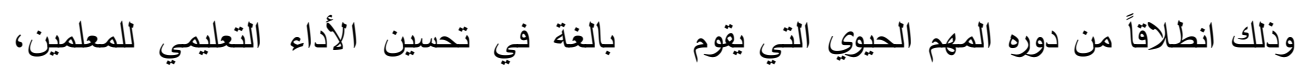

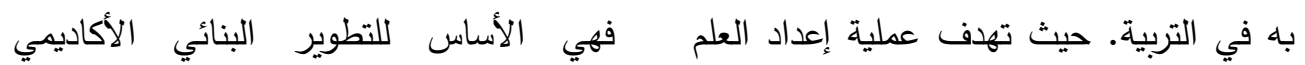

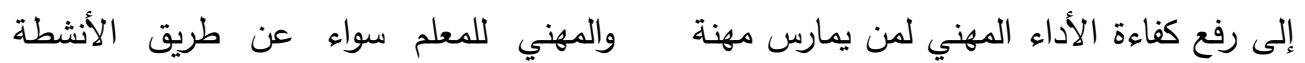

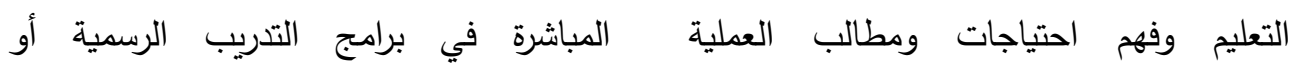

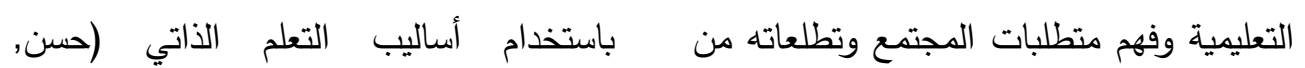

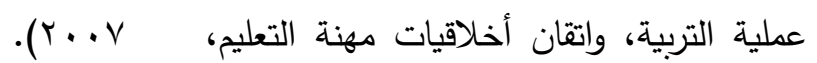

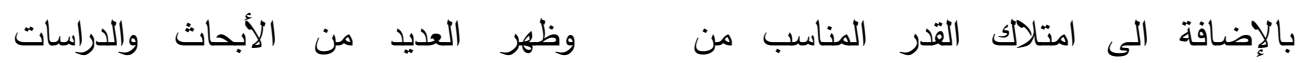
المعرفة التي عين المعلم على تقديم التخصص العلمية والتي تؤكد على أهية اكتساب مهارات القرن الحادي والعشرين، والارتقاء بمهنة التعليم

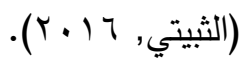
تبعاً للالك فقد احتلت مسألة اعداد المعلم وتطوير برامج اعداد المعلم وتتميته مهنياً

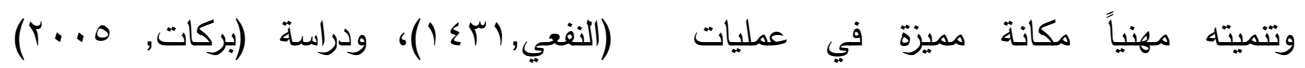

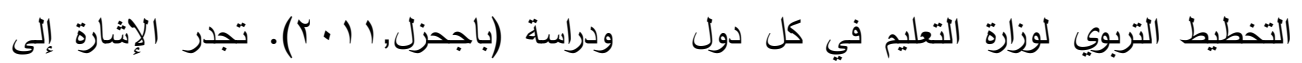

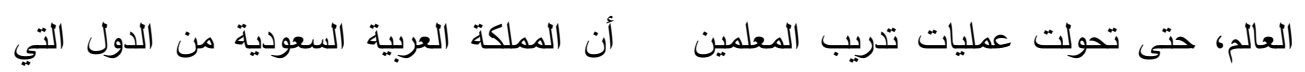

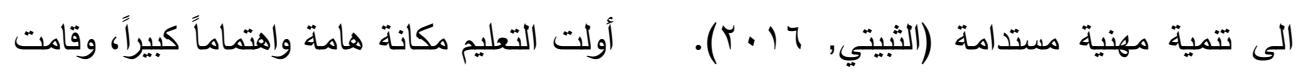

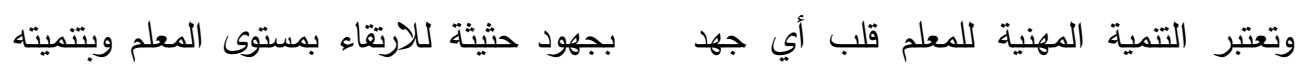
يبذل لإصلاح أي نظام تعليمي. فمعلم القرن المهنية، وقد استمر هذا الاهتمام إلى السنوات

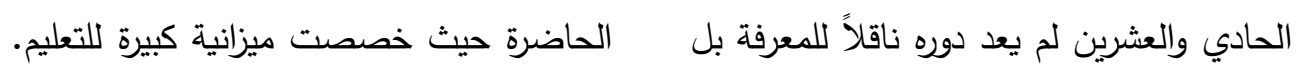

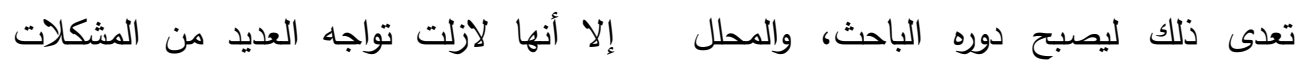
العلمي، والمختص، والمساعد، والموجه، التي تحول دون تحقيق هدفها بتطوير المعلم 
واعداده اعداداً جيداً, وهذا ما أثارت إليه كثيراً الدول المتقدمة في مجال إعداد المعلم وتتميته

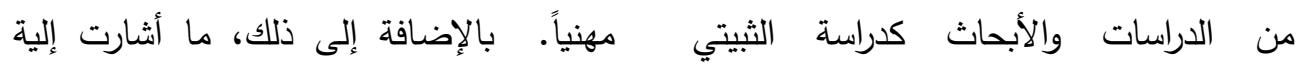

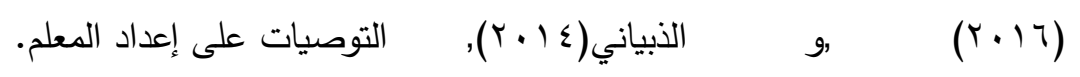

ومن الدول الرائدة والمتقدمة في مجال

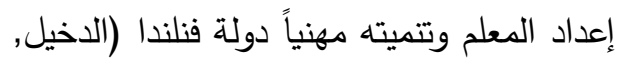

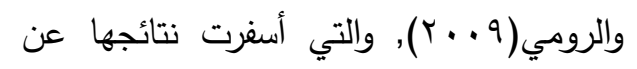

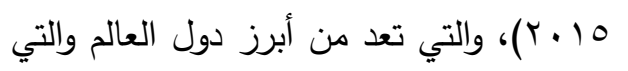

ضعف في برامج إعداد المعلمين وعدم كفاءة ولتئ

مخرجاتها, كما أشارت إلى عدم تلبية برامج

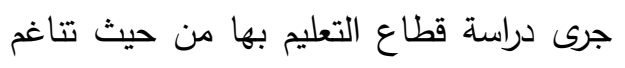

التدريب أثناء الخدمة لحاجات المعلمين للتنمية

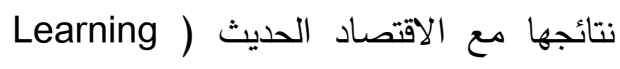

المهنية, مما أوصت بضرورة تطوير برامج

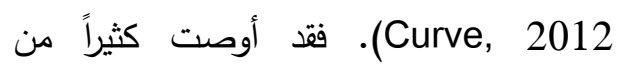

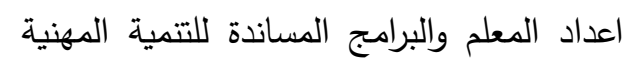
الدراسات إلى الاستفادة من تجربتها في اعداد

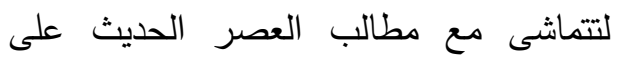
المعلمين وتتميتهم مهنياً، حيث قدمت نموذجًا متميزًا بتفوقها على دول العالم في برنامج اعتبار أن المعلم هو الركن الأساسي في لعيدي العملية التعليمية.

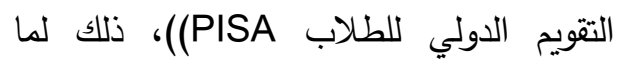
أولته من اهتمام بالغ في إعداد المعلم وتطويره؛ إيماناً منها بأن المعلم أساس نجاح لعالع العملية التعليمية، وأن كفاءة الخريج تتوقف على كفاءة

كما أكدت كلا من موران وكلارك (Moran \&Clarke,2012) إلى أن : نتائج البلاد الممتازة باستمرار في منظمة التعاون والتتمية في الميدان الاقتصادي (برامج لتقييم الطلاب الدوليين) مما لا شك فيه يرجع إلى الى الى إنيل

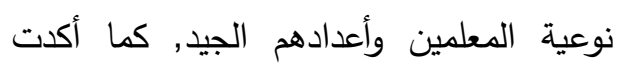
نئيمي (Niemi,2015) على أن فنلندا دولة

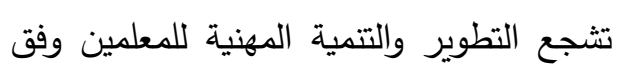
مبدأ التعلم مدى الحياة, هذا وقد أشار العسيري ( (Y) إلى أن اعداد المعلم وتتميته مهنياً

كما أشارت توصيات مؤتمر معلم المستقبل

إعداده وتطويره والمنعقد بكلية التربية بجامعة دوصنية

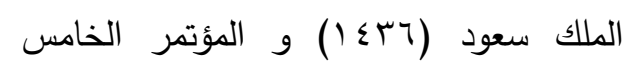
لإعداد المعلم الذي أقامته كلية التربية بجامعة الماتدرد

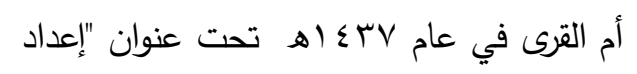
وتدريب المعلم في ضوء فطام فالب التتمية

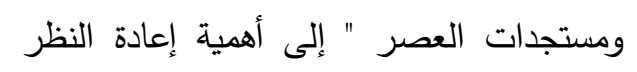
في فلسفة برامج إعداد المعلم واهدافها وتتميته

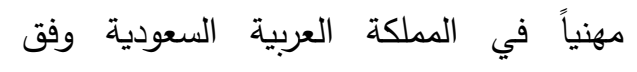
توجهات خطط التتمية والتطلعات المستقبلية في ضوء مطالب العصر العالمية, ووِفق برامج عالية الجودة توفّر لله أرقَى الكفايات وأحدثها، وأجود الدعايير في الاختيار والإعداد والتدريب والتقويم، بمستوى يليق بدوره الفاعل في بناء

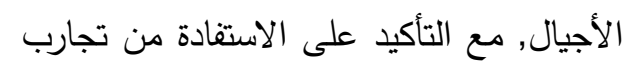


أظهرت ضعف مخرجات كليات المعلمين في المملكة العربية السعودية وعدم كفاءتها, وتثير

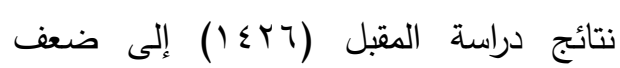

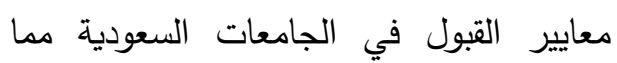
تضمن انتقاء مقنن لمعلم المستقبل. وتتفق

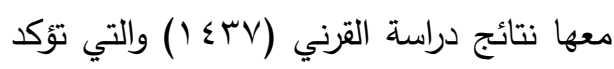
على وضع معايير واضحة لاختيار المعلمين في كلية التربية.

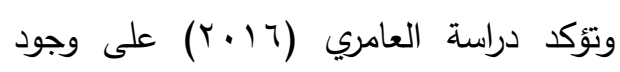

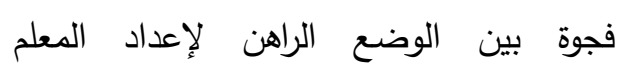

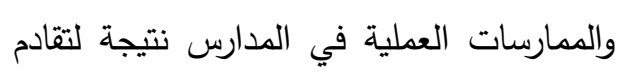
خطط كليات التربية وغياب التتسيق والتكامل بين كليات التربية والجهات المشرفة على

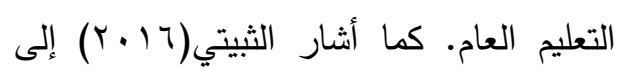
ضعف المعلمين في الجانب العلمي والتربوي وأن نسبة المعلمين الذين استفادوا من برامج التدريب تعد ضعيفة. ويؤكد رئيس المركز الوطني أن نسبة اجتياز المعلمين والمعلمات ولتئن

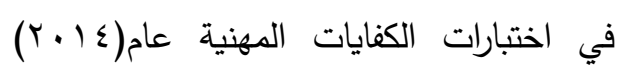

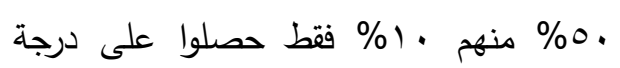

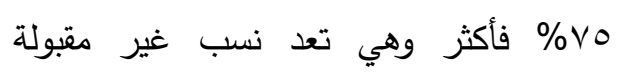

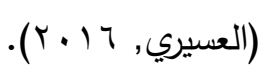

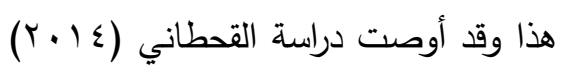
بضرورة تطوير المعلمين مهنياً وتدريبهم وتشجيعهم لتطوير أنفسه. كما ويؤكد الزايدي

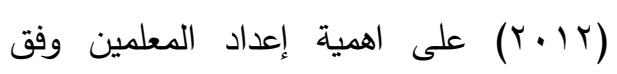
كفايات ومهارات القرن الحادي والعشرين. كما
بدولة فنلندا يتسم بالجودة العالية وبما ينسجم

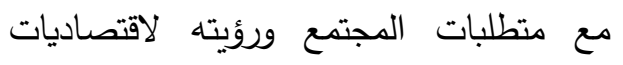
المستقبل ؛ وهذا ما دعي البحث الحالي أن

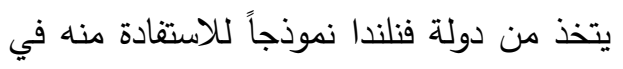

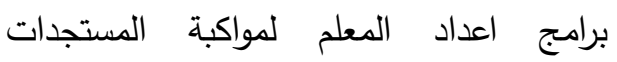
التربوية. مشكلة البحث : ظهرت الكثير من المشكلات التعليمية نتيجة للتطورات المتسارعة في هذا العصر،

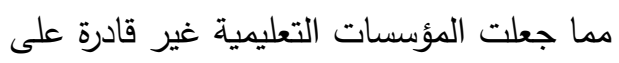

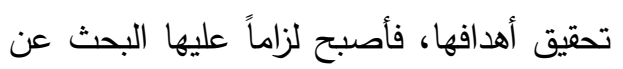
طرق واساليب حديثة لمواجهة تلك المشكلات والاستفادة من تجارب الدول الرائدة وتكيفها مع لعائي

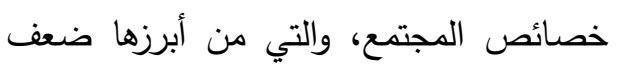
إعداد المعلم وتأهيله مهنياً، كما ورد في تقرير ائهن

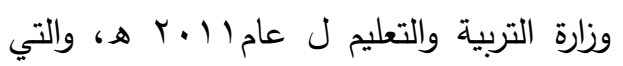

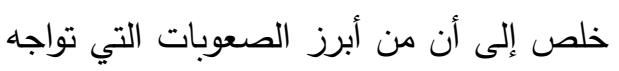
التعليم العام في المملكة ضعف لترن تأهيل المعلمين. ومع أن عملية إعداد المعلم في المملكة العربية السعودية في الوقت الراهن تمر بمرحلة تحول تستهف تطويراً شاملاً مراعياً للجودة لتران

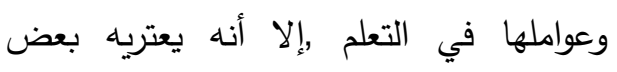

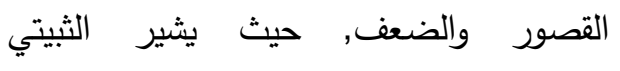

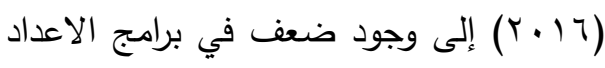
التربوي في كليات المعلين في المملكة وعدم مواكبتها للتطورات العالمية والدولية, وتتقق فئق

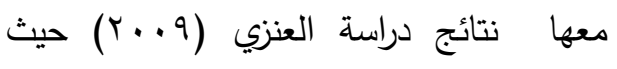




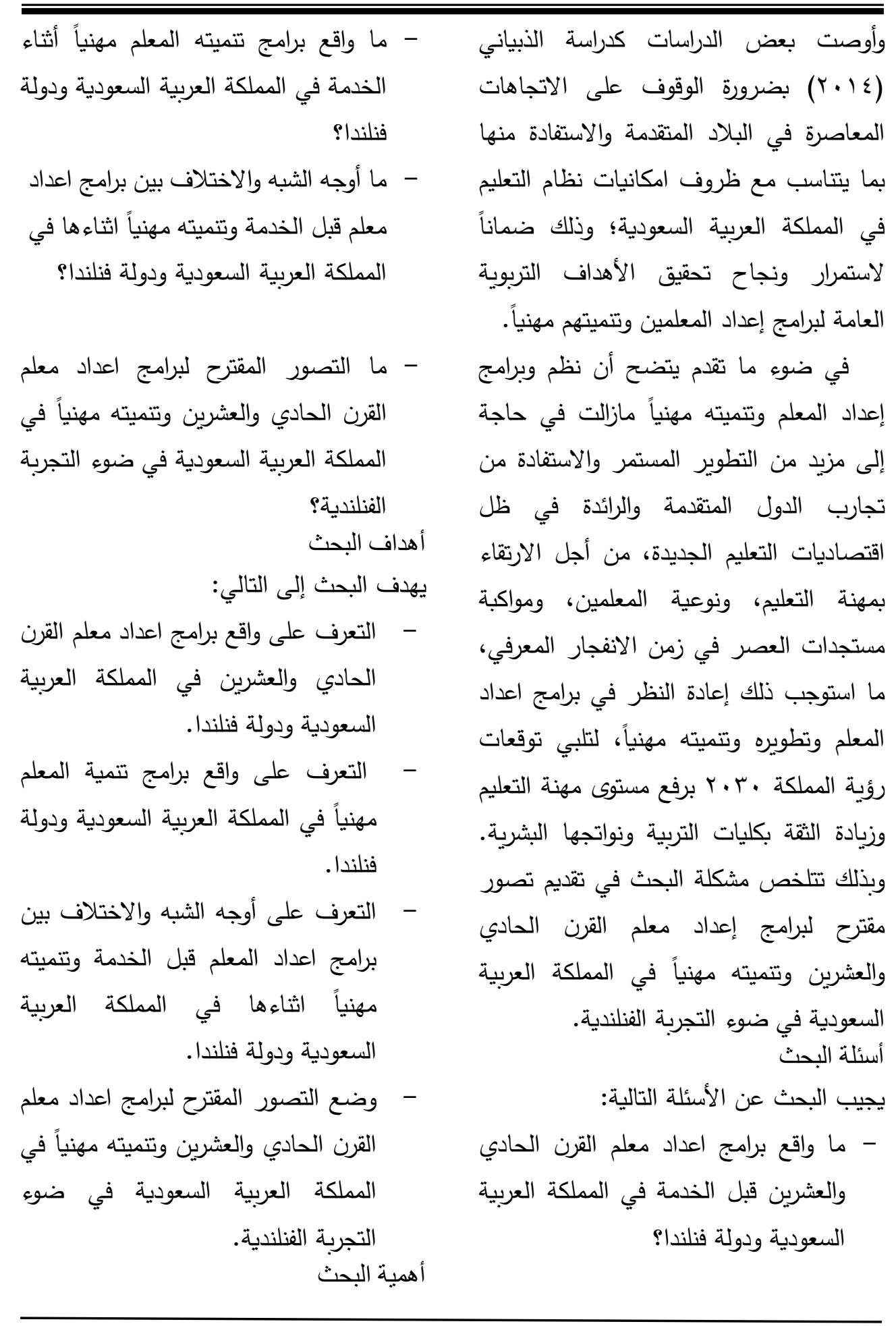


يعتمد البحث الحالي على المنهج التحليلي

المقارن، باعتباره منهج مناسب لتحقيق أهداف

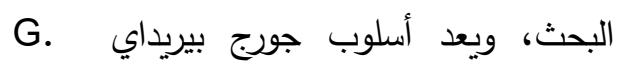

Bereday

الخطوات الأربع وهي) الوصف والتفير

والموازنة والمقارنة (أنسب وأيسر صور التحليل

المقارن؛ فهو يتمثّل في طريقة حل المشكلات

والتي تمكن من اختيار المشكلة ودراستها

وتفسير ما يتصل بخبرات الدولتين في برامج

اعداد المعلم وتتميته مهنياً، وتحديد أوجه

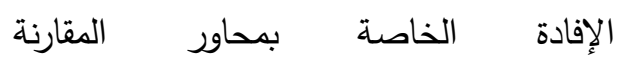

(الزكي, ع • • (rم).

مصطلحات البحث

برامج اعداد المعلم: برامج مخططة

ومنظمة وفق النظريات التربوية النفسية والتي براتي

تقوم بها مؤسسات تربوية متخصصة لتزويد

الطلاب المعلمين بالخبرات الثقافية والعلمية

بهدف تزويدهم بالكفايات التعليمية الي تمكنهم

من النمو في المهنة وزيادة انتاجاتهم التعليمية

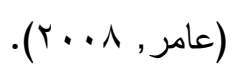

(التعريف الإجرائي): ويقصد بها البرامج

المعدة مسبقاً لإكساب المعلم الطالب المهارات

والمعلومات والتدريبات الازمة لمزاولة مهنة

$$
\text { التدريس بعد التخرج. }
$$

التنمية المهنية للمعلم: هي عملية منظمة

مدروسة لبناء مهارات تربويـة وإدارية وشخصية

$$
\text { تتمثل أهمية البحث في الآتي: }
$$

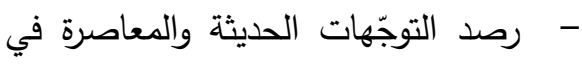

برامج اعداد المعلم وتنميته مهنياً في دولة

فنلندا.

- المساهمة في تحقيق رؤية المملكة

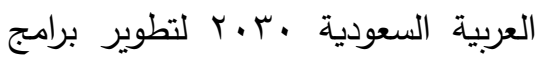

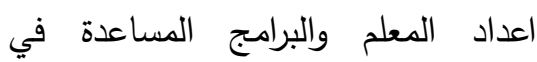

التتمية المهنية، ليكون أكثر ارتباطاً

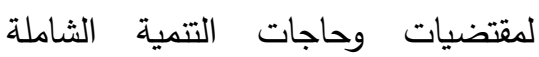

ل ل للأفراد والجماعات.

- تزويد القائمين على التعليم في المملكة

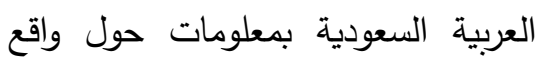

برامج إعداد المعلمين والبرامج المساعدة

في تنميتهم مهنياً.

حدود البحث:

- - الحدود الموضوعية: تناول البحث برامج

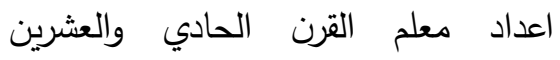

والبرامج الدساعدة في تتميته مهنياً في العين

المملكة العربية السعودية وفنلندا.

- الحدود المكانية: دولة فنلندا كدوله

للمقارنة والاستفادة من برامجها في اعداد

معلم القرن الحادي والعشرين وتتميته مهنياً

في الملكة العربية السعودية باعتبارها

دولة رائدة في ذلك.

- - الحدود الزمانية: الفصل الثاني من العام

$$
\text { منهج البحثي شبأ ام. }
$$


فقد أجرى كلاً من المفرج والمطيري وحمادة

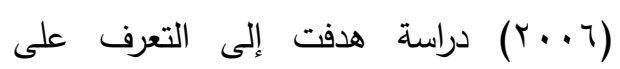
الاتجاهات المعاصرة في إعداد المعلم وتتميته مهنيًا ، وهي دراسة مكتبية تقوم علي مسح جميع أدبيات الدراسات السابقة ( العربية دراسية

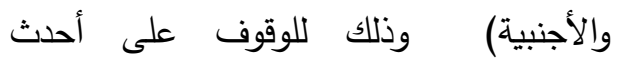
الاتجاهات المعاصرة والنظم لإعداد المعلم وتتميته مهنياً, وقد أظهرت الدراسة الاهتمام المتزايد للدول المتقدمة والنامية بالاتجاهات الحديثة في مجال إعداد المعلم وتتميته مهنيًا في مراحل التعليم العام، كذلك توصلت الدراسة إلى أن إعداد المعلم عملية مستمرة تشمل الإعداد قبل الخدمة والتدريب في أثناء الخدمة

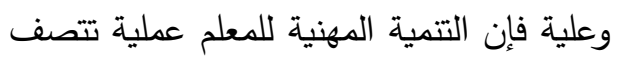
بالديمومة ولا تتنهي عند تخرج الطالب من

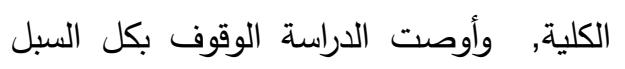
على الاتجاهات العالمية المعاصرة في البلاد المتقدمة في مجال إعداد و تدريب المعلم و

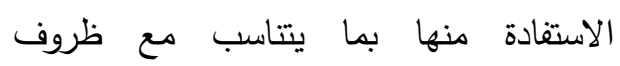
وإمكانيات نظام التعليم في الكويت والأخذ بنظام الإعداد المتكامل للمعلم بحيث يعد في

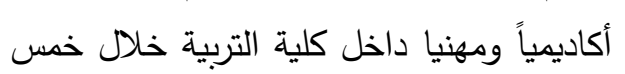

$$
\text { سنوات . ل ساديا }
$$

كما قام بخش (• ( • (Y) بدراسة هدفت إلى

الوقوف على أهم الإجراءات التي ينبغي أن أن إنى تتخذ لتحسين إعداد المعلم في المملكة العربية

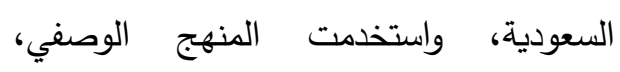

جديدة، تلزم المعلمين لقيامهم الفعال بالمسؤوليات اليومية، أو ترميم ما يتوفر لديهم

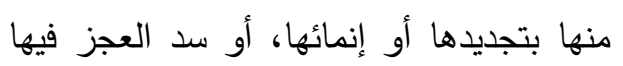
لتحقيق غرض أسمى وهو تحسين فعالية

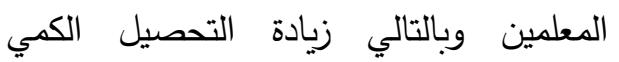
والنوعي للمعلمين) نصر ، ع . . ؟). (التعريف الإجرائي): ويقصد بهان عمليات حصول المعلم على المهارات والمعلومات بثكل يؤدي إلى تطور مستواها، سواء كان بمجهوده أو عن طريق برامج تدريبية. الأًا الأبحات السابقة: العربية: نظراً لأهمية دور المعلم في نجاح العملية التعليمية كافة، فقد عنيت كثير من المجتمعات الحديثة بوضع النظم التي تكفل إعداده قبل الخدمة ومساعدته على التتمية المهنية لئية باعتبارها عملية مستمرة، تمكنه من أداء دوره

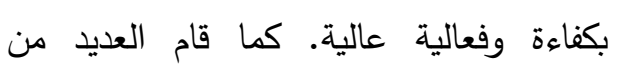

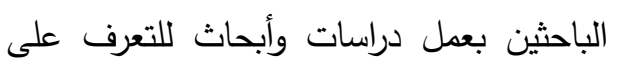
واقع اعداد المعلم وتتميته مهنياً، وأبرز المشكلات والاتجاهات العالمية، فبمقدار الاهتمام بنوعية المعلم وإعداده وتأهيله مهنياً إنما يعكس الإحساس بالمسؤولية تجاه مستقبل الأجيال ومدى الحرص على توفير الخدمات التعليمية لها ل الاجياي ومدى 


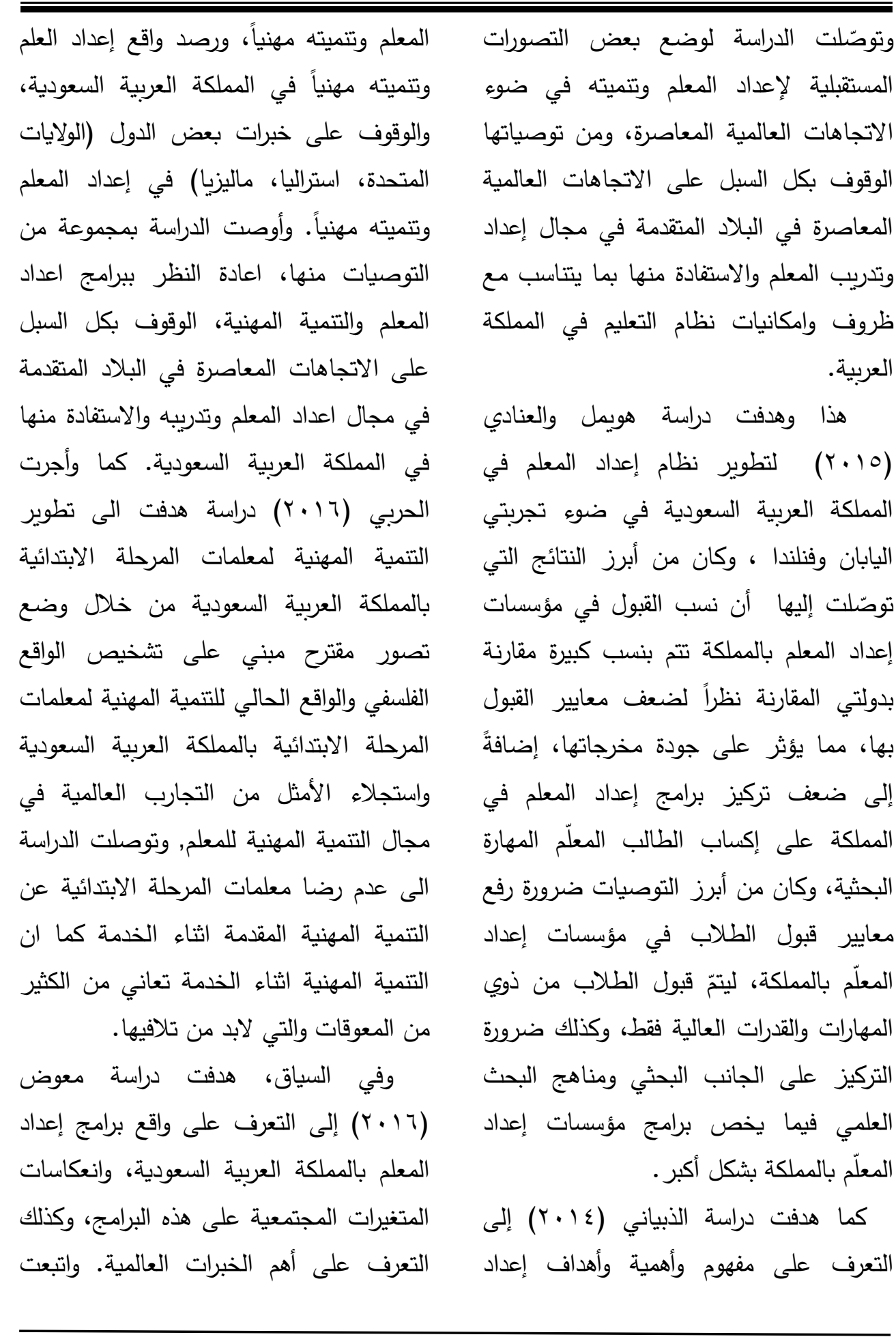


‘Areesophonpichet, 2015 Vibulphol Rukspollmuang)،Loima إلى تحليل برامج إعداد المعلم التي تم تحديثها مؤخراً في جامعتين، أحدها في فنلندا والأخرى

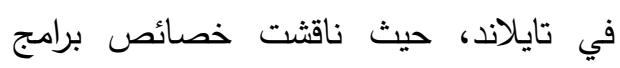
اعداد معلمين المدارس الابتدائية والثانوية في تياني الجامعات المختارة، كما ناقشت دور وأهمية مهارات القرن ال اب لبرامج إعداد المعلمين

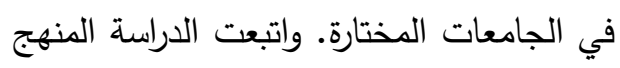

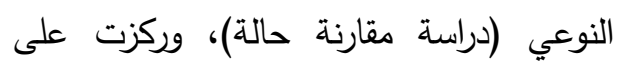
المهارات الحديثة والبرامج الدقدمة. وكانت أدوات الدراسة تحليل الوثائق استبيان. عينة الدراسة ثلاث من أعضاء هيئة التدريس في كل التاني جامعة والذي كان لهم الدور في تحديثات الحديثة على برامج إعداد المعلمين، وكثفت

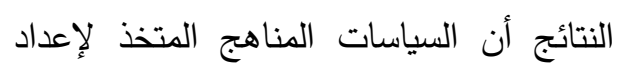
المعلمين في البلدين كانت مختلفة. في حين أن البرامج الجامعة التايلاندية تركز أكثر على فلى فلى فين المقررات، وأما الجامعة الفنلندية كان لهم رؤية

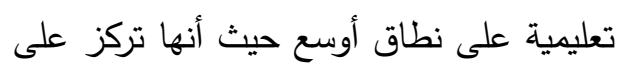

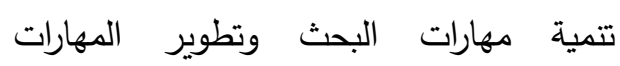
المختلفة الأخرى واعتبرت ان ممارسة التدريس ذات أهمية كبرى. واوصت الدراسة إلى اجراء المزيد من البحوث حول إعداد المعلمين مهنياً. وفي دراسة قامت بها كلاً من موران وكلارك (Moran \&Clarke,2012) هدفت دوفي دوران الى البحث عن الطرق التي تسهم في التطور
الدراسة المنهج الوصف التحليلي، وتوصلت النتائج إلى تتوع مظاهر اهتمام المملكة بإعداد المعلم، من خلال المؤتمرات واللقاءات المنعقدة بشأن تطوير برامج الإعداد بالمملكة، وأيضا

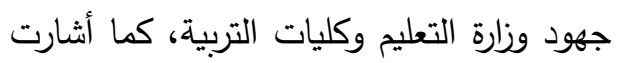
النتائج أن برامج إعداد المعلم بالمملكة تواجه

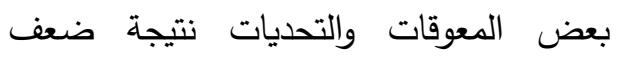
مواكبتها للتغييرات المحلية والعالمية، وعدم تحقيق بعض متطلبات الاعتماد الأكاديمي.

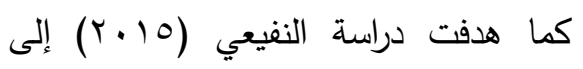
تحديد المتطلبات الإدارية والفنية والمادية والبشرية الازمة لتوطين التدريب بالمدارس ولإنه الثانوية كاتجاه حديث للتمية المهنية المستدامة من وجهة نظر المديرين والمعلمين بمدينة مكة المكرمة. وتوصلت الدراسة إلى أهمية توافر المتطلبات الإدارية والفنية والمادية والبشرية لنجاح توطين التدريب في الددارس، فرغم اهميته الا ان هناك قصور في تلبية متطلبات

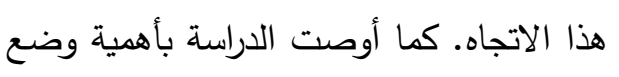
آلية لتوفير المتطلبات السابقة بكل مدرسة أو الواه من خلال اشتراك مجموعات المدارس المتقاربة في توفير قاعة تدريب مجهزة وهيئة متخصصة

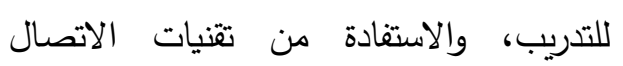
الإكترونية الحديثة في التدريب عن بعد داخل

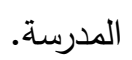
ثنانياً: الأبحاث الأجنبية: الجية

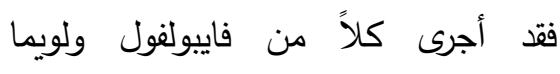

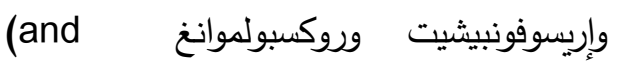


التعليم، ويتم ذلك في مؤسسات خاصة بإعداد المعلمين، وتعمل هذه المؤسسات في إطار فلسفة وأهداف ونظام دراسة ونظام تقويم. ويقصد ببرامج إعداد المعلم، الاستعداد أو ونظه التحضير للمعلم قبل دخوله الصف.

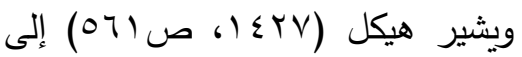

أن " قبول الطالب الذي لا يملك الاستعدادات والقدرات والميول المهنية والصفات الثخصية لان الثية التي تئهله للعمل بعد تخرجه في مهنة التعليم

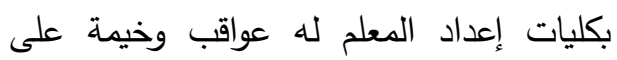
مستقبل الطالب المهني من ناحية، ومن ناحية

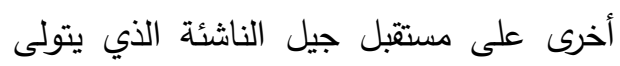

$$
\text { مسئولية إعداده وتعليمة " ملئيل جيل }
$$

هذا وتثير كثير من البحوث والدراسات التربوية إلى أن هناك ثلاثة جوانب أو أبعاد

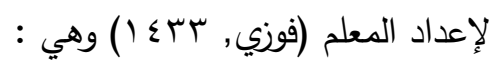
الجانب الثقافي: فلا بد للمعلم أن يكسب أولاً ثقافة المجتمع بكافة جوانبها من خلال فهمها

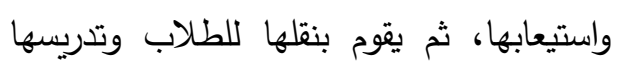

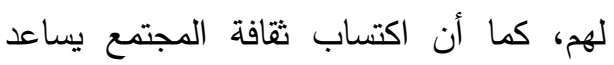
المعلم على فهم المجتمع الذي يعمل فيه.

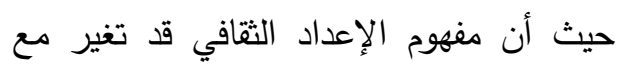

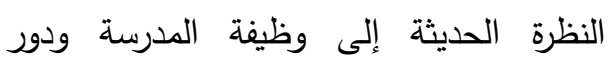
المعلم، فبدلاً من الاهتمام بكثير من المعارف

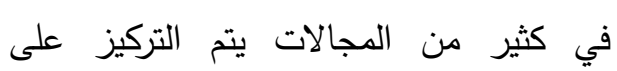
الجوانب التي يهدف إلى تعليم الطالب كيفية
المهني للطلاب المعلمين في كليات التربية بالمقارنة بين فنلندا وايرلندا الثمالية حيث تم اختيار جامعة (هلسنكي) في فنلندا وجامعة (أولستر) في ايرلندا , حيث تسعى على وجه

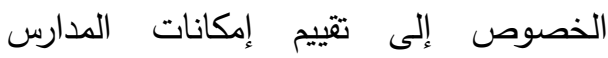
الخاصة بتدريب الطلاب المعلمين قبل الخدمة (التربية العملية) في إيرلندا الثمالية, وقد تم

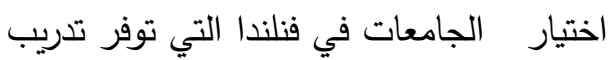

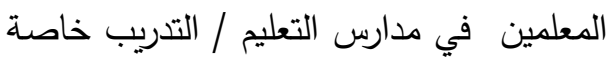
مرتبطة بالجامعة , وقدتم اختيار النموذج الفنلندي للمقارنة بسبب نتائج البلاد المتازة

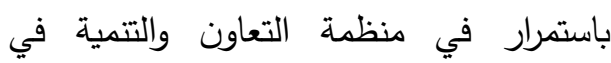
الميدان الاقتصادي (برامج لتثقييم الطلاب الدوليين) مما لا شك فيه أن جزء منه يعود لنوعية المعلمين, وتوصلت الدراسة الى أنه النه يمكن إدخال عنصر المدرسة في التعليم والتدريب المهني, مع مزيج من الواقعية والحذر ، فإن الأساس المنطقي لمدارس التدريب

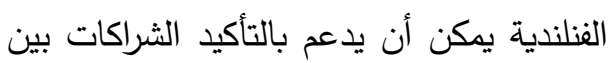

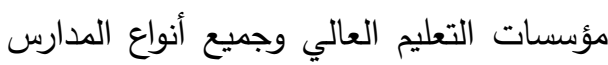
داخل كل منطقة مجتمع تعلم , أي بالمفهوم

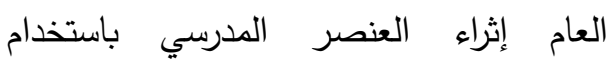
الشبكات التعاونية القائمة للمدارس.

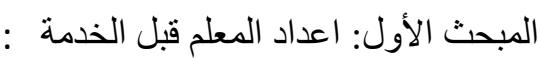
الإعداد قبل الخدمة يعتبر الحلقة الأساسية لنظام إعداد وجاهزية المعلم، والتي تختص بتدريب المعلم الطالب وإتقانه للمهارات والكفايات المهنية اللازمة لممارسة مهنة 
مهمة لمعرفة ما حققه الطالب من دراسته النظرية خلال فترة إعداده الماضية. كما تتبع معظم دول العالم في إعداد المعلمين نظامين أساسيين هما: النظام التكاملي (المتوازي) :ويتم في هذا: النظام المزج بين المقررات التخصصية والمقررات التربوية، بحيث يقوم الطالب لدرات بدراستهما معاً خلال مدة إعداده التي تصل إلى لى لئل أربع سنوات. ومن مزايا النظام التكاملي في إعداد المعلم ما يلي: توفر الاستعداد النفسي مدي

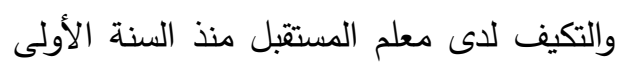
لالتحاقه بالكلية، توافر التزامن والموازنة بين

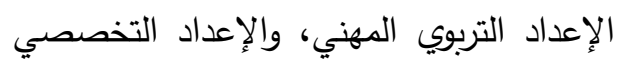

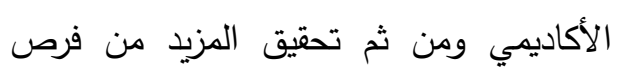

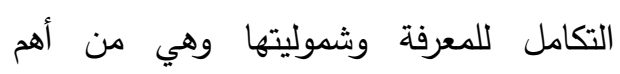
الاتجاهات التربوية المعاصرة.

النظام التتابعي: ويقوم هذا النظام على

فصل المقررات التخصصية عن المقررات

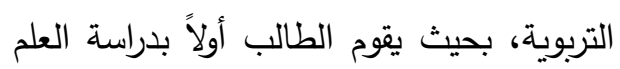

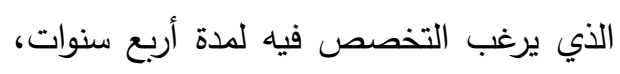
دون أن يدرس أية مادة تربوية خلال هذه الفترة، ثم يقوم بعد اجتيازه وإنهائه لدقررات لثرنه التخصص وحصوله على الدرجة الجامعية بالالتحاق ببرنامج (الدبلوم العام في التربية)

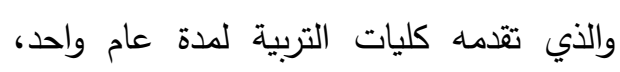

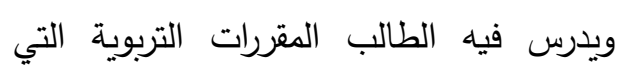
تؤهله لمهنة التدريس.
الحصول على المعرفة، واستخدام البحث العلمي لحل المشكلات. الجانب الأكاديمي (التخصصي): ويقصد به

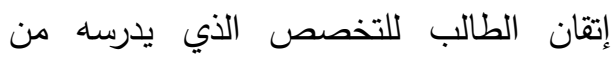
خلال إجادته للمقررات المتخصصة في العلم الذي يرغب فيه، بحيث يتمكن من موضوعات

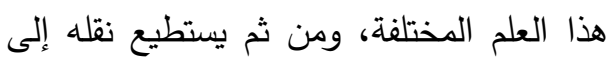

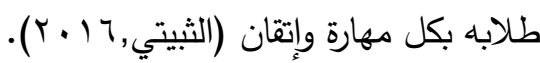
الجانب التربوي (المهني): إن الإعداد التربوي

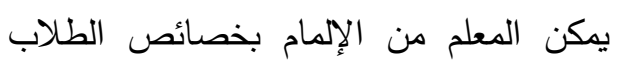
والطرق التربوية للتعامل معهم وفق المرحلة العمرية التي يعيشونها، بالإضافة إلى اختيار طريقة التدريس المناسبة لهم. كما يشمل الجانب المهني - إضافة إلى لى لقدئ المقررات التربوية النظرية - جانباً مهنياً تطبيقياً وهو ما يعرف بالتربية العملية، بحيث يقوم الطالب بالتطبيق الميداني لعملية التدريس لئنس في إحدى المدارس، وذلك في الفصل الأخير

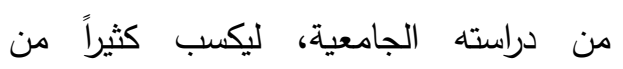
المهارات والأساليب التدريسية التي لا يكفي لهيكي دراستها نظرياً فقط، وإنما يحتاج اكتسابها إلى لى لئي ممارسة عملية على أرض الواقع.

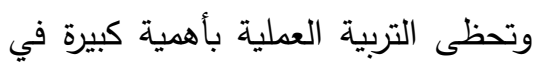
جانب الإعداد المهني للمعلم، باعتبارها المحك ليك لئه

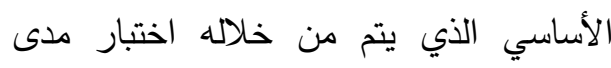

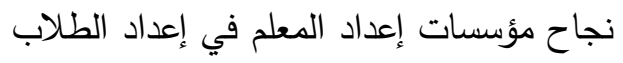

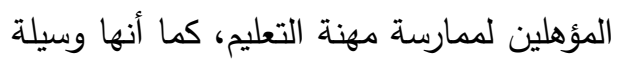


ومن مميزات النظام التتابعي في إعداد الجديد في مجال التكنولوجيا والمعرفة، فمن

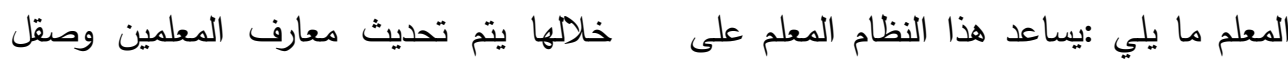
التعمق في تخصصه قبل الالتحاق بكلية خبراتهم ومهاراتهم المهنية، كما ينظر للتنمية التربية، يساعد الدولة على سد العجز في المهنية بأنها ضرورة لرفع كفايات المعلمين التخصصات المختلفة وخاصة في المدارس الذين التحقوا بالمهنة دون إعداد كاف ولمواجهة الفنية، حيث يتيح هذا النظام للطالب أن يصل أوجه القصور في برامج الإعداد بكليات التربية

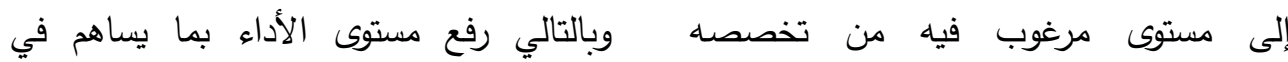

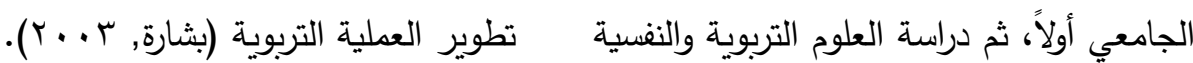

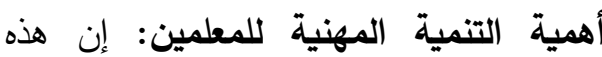
التطورات جعلت الدول تهتم بالتتمية المهنية لمعلميها الذين هم عصب العملية التعليمية

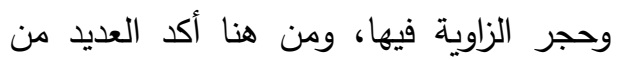

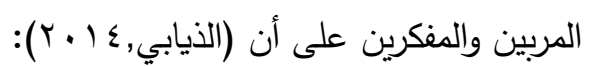
- - الاهتمام بالتتمية المهنية للمعلمين يثكل

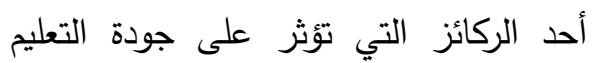
العلوم النفسية والتزبوية , تغير أدوار المعلم : المدرسي. - - التتمية المهنية لا تتم بصورتها المشرقة

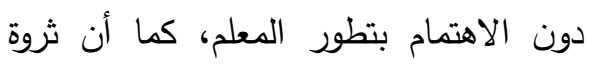
الأمم لن تلبث أن تكون عبارة عن القدرات

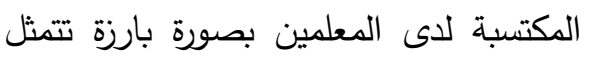

في تعليمهم وخبراتهم ومهاراتهم وصحتهم. أهداف التنمية المهنية للمعلمين: إن أهداف التتمية المهنية للمعلمين ليست التهنيت

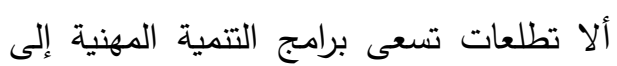

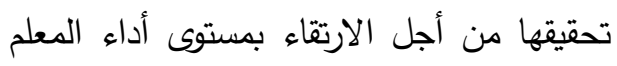

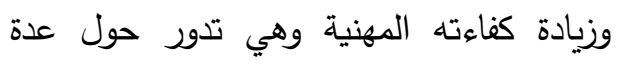
نقاط منها (الدريج وجهاد ,0 . . ץ):

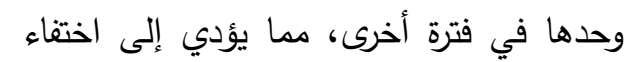

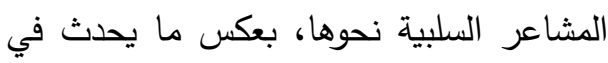

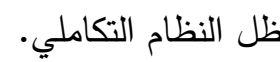

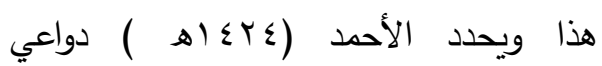
الإعداد قبل الخدمة, بما يلي تزايد أعداد المتعلمين ,التقدم العلمي الكبير.., تقديم وسائل المعرفة الطريقة العلمية في التعليم , تطور لم يعد المعلم مجرد ملقن للمعرفة , كما كان في المدرسة التقليدية , بل أصبح عليه أن

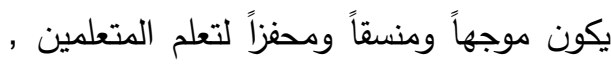

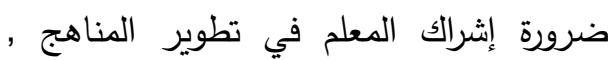
مهين التعليم , تطبيق شعار ديمقراطية التعليم ( التعليم للجميع ) : ويتم ذلك من خلال

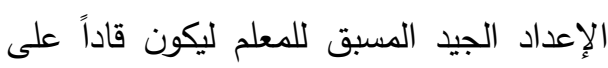

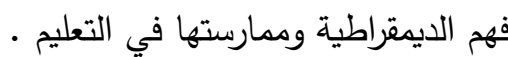

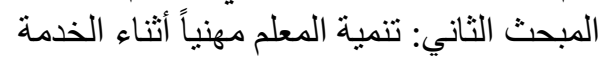
تعد التتمية المهنية من الاستراتيجيات المطلوبة لخروج النظم التعليمية من أزمتها والاستجابة لمتطلبات ثورة المعلومات ومتابعة

\section{$r \cdot \varepsilon$}


تحديث المعرفة والوقوف على كل ما هو الصفية، الحلقات النقاشية وورش العمل، جديد ,تحسين الأداء الوظيفي وتطويره وتحديثه التوطين في المدوفي المدراس، ومجتمعات الممارسة

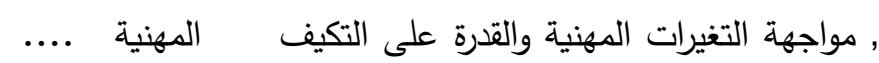

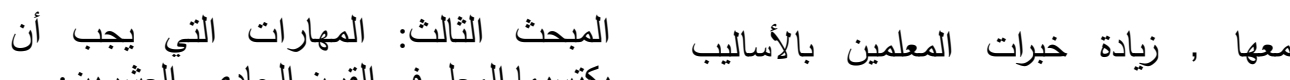
يكتسبها المعلم في القرن الحادي والعشرين: إن أهم المهارات التي ينبغي أن يمتلكها

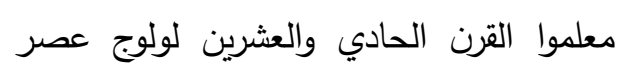
الاقتصاد المعرفي سعيًا لبناء مجتمع المعرفة

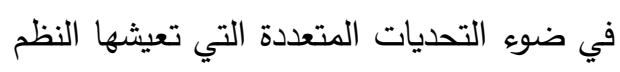
التربوية، والواجب تضمينها في برامج إعداد المعلمين، تتمثل في: (تتمية المهارات العليا للتفكير، إدارة المهارات الحياتية، إدارة قدرات الطلاب، دعم الاقتصاد الدعرفي، إدارة

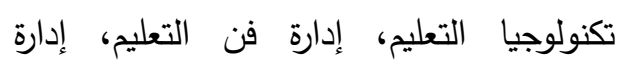

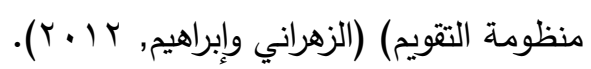
وقد أشار كلاً من ويتًا وكروسب ولاني (Wittea, Grossb \& Latham, 2015) إلى بعض المهارات التي يجب تضمينها في محتوى مناهج برامج إعداد المعلمين في القرن ا ب منها: ممارسة حقوق والتزامات المواطنة على المستوى المحلي والوطني, فهم دور الاقتصاد في المجتمع على الصعيد العالمي, والنظام الغذائي السليم , التحقيق في القضايا البيئية وتحليلها، وتقديم استنتاجات دقيقة عن

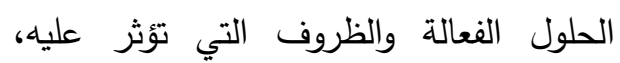
إثبات النزاهة والسلوك الأخلاقي, استخدام المهارات الثخصية والقيم الأخلاقية, التتمية الذاتية, تحليل وتقييم الأدلة والحجج والمطالبات الحديثة في التدريب , القدرة على الابتكار والإبداع , معالجة أوجه النقص أو القصور في

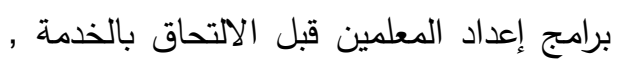
إطلاع المعلمين على المستجدات الحديثة في برات بلدي مجال طرق التدريس وتقنيات التدريس ومحتوى إعلين المنهج للطلاب , مساعدة المعلمين الجدد على

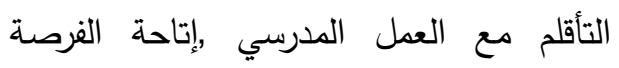
للمعلمين للحصول على مهارات جديدة وتوسيع

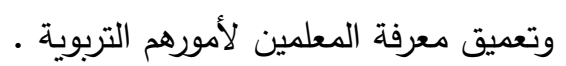
خصائص التنمية المهنية للمعلمين: يمكن إبراز أهم خصائص التتمية المهنية

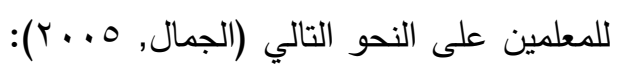

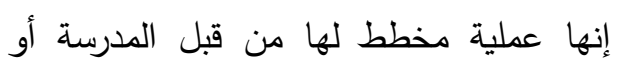

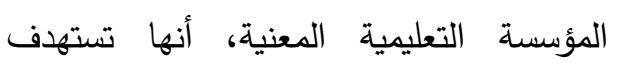
تحسين أداء المعلمين في كافة الجوانب، أنها تبدأ منذ تخرج المعلم والتحاقه بالمهنة وتستمر

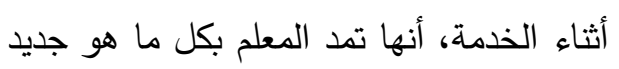
في مجال تخصصه لتنمية مهاراته المهنية، أنها تعد عمل من أعمال الإدارة المدرسية وأحد وظائفها المهمة لتحقيق جودة الأداء. كما أنه النه يتم تحديثها من خلال عدة مصادر وأساليب مختلفة منها التدريب أثناء الخدمة، التعلم

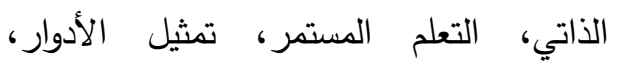
المؤتمرات والندوات، التدريب عن بعد، الزيارات 
سنوات، وبالتالي تتيح أنظمة إعداد المعلم

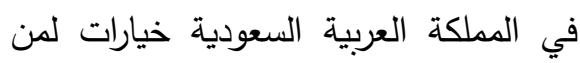
يرغب العمل في مهنة التعليم. كما يخضع الطالب المعلم بعد التخرّج لاختبار (كفايات المعلمين)، وذلك بغرض الحرص على لئ لئل التحاق الكفاءات المؤهلة بمهنة التدري، ودمصن وتتألف اختبارات المعلمين من اختبارين أساسيين هما الاختبار العام الذي يشمل كافة المجالات التربوية، والذي يغطيه عدة معايير، والعلوم التربوية، واللغوية، والكمية،

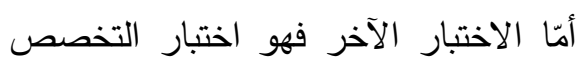

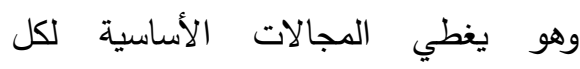
تخصص من التخصصات التدريسية، ومدّة صلاحية هذا الاختبار خمس سنوات.

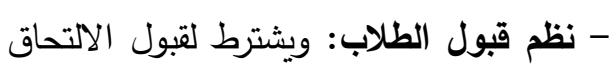

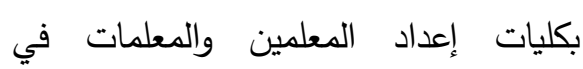
المملكة العربية السعودية عدة شروط من

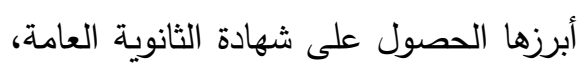
وحسن السيرة والسلوك، وأن يكون لائق طبياً، والأخذ بنسبة معيّنة من نتيجة الثانوية

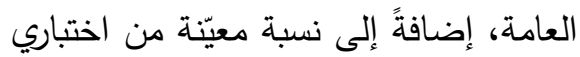
القدرات والتحصيلي، اللذين ينظمهما المركز الوطني للتقويم والقياس. نظراً لأهمية دور المعلم فقد عنيت المجتمعات الحديثة باختيار العناصر التي تعد لمهنة التعليم طبقاً لمعايير ومواصفات دقيقة.

$$
\begin{aligned}
& \text { والمعتقدات بفعالية , تقسير المعلومات } \\
& \text { واستخلاص النتائج على أساس أفضل تحليل. } \\
& \text { عرض النتائج ومناقشتها: }
\end{aligned}
$$

الإجابة عن السؤال الأول :واقع برامج إعداد معلم القرن الحادي والعشرين في كلٍ من المملكة العربية السعودية وفنلندا. • واقع برامج إعداد المعلم في المملكة العربية السعودية سيتم تتاول مختلف جوانب إعداد المعلم بالمملكة بناء على استقراء الواقع وما جاء في لتاول إعل

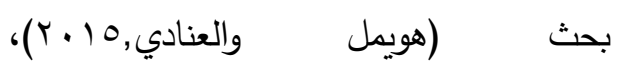

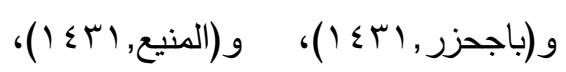

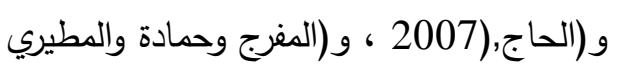

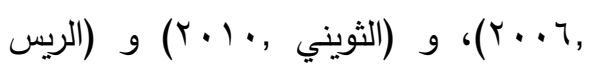
,2016).

برامج إعداد المعلم: إن الاتجاه الراهن في تنظيم عملية إعداد المعلم أن يتم هذا الإعداد إداد

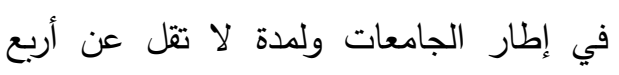
سنوات وذلك ضماناً لتخريج المعلمين من ذوي الكفاية العلمية والتربوية والمهنية، وثمة نظامان

$$
\text { هنا هما: }
$$

•النظام التتابعي :يلتحق فيه الطالب المعلم بعد الدراسة الجامعية ويدرس لمدة سنة واحدة أو سنتان، بإحدى كليات التربية بهدف الحصول على الدبلوم التربوي.

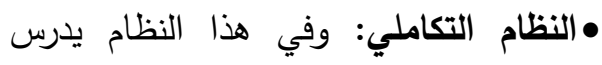
الطالب المعلم المقررات التربوية والتخصصية في ذات الوقت على مدى أربع 
الاختبارات التحريرية التي يخضع لها الطالب المعلم نهاية كل فصل دراسي لكافة المقررات. واقع برامج اعداد المعلم في فنلندا

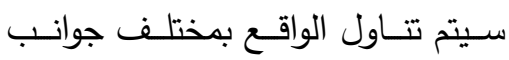
إعداد المعلم بناء على استقراء الواقع وما

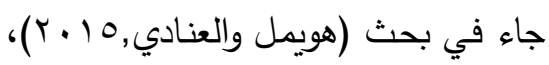

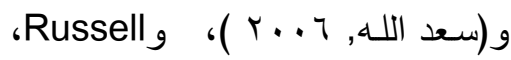
و 2015) (Poole and

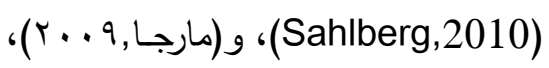

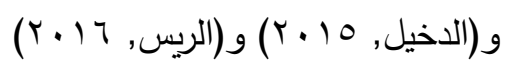
برامج إعداد المعلم: برامج إعداد المعلم الفنلندي يتبع النموذج الأوروبي الذي براعي يتضمن مسارين مختلفين بشهادتين مختلفتين، الثهادة الأول يحصل عليها عند حصوله على درجة البكالوريوس وشهادة

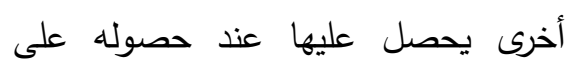
درجة الماجستير، وتعتبر درجة الماجستير

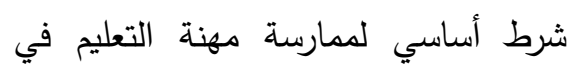
فنلندا. وهناك اختلاف أساس في نظام

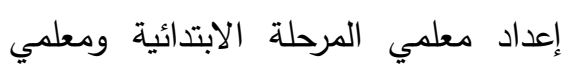
المرحلة الثانوية, فمعلم المرحلة الابتدائية يشترط عليه أن يتخصص في قسم التربية

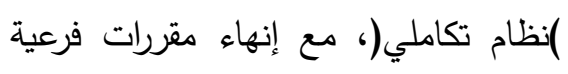
في مادتين من مناهج المرحلة الابتدائية,

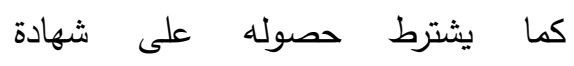
البكالوريوس بعد إكماله لثلاث سنوات

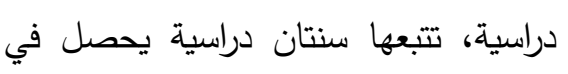

- جوانب الإعداد: يشمل إعداد المعلم في دماد المملكة ثلاثة جوانب هي:

الجانب الأكاديمي: وهو يتضمّن التعمق في دراسة تخصص في المجالات العلمية التي لتصني سيقوم المعلم بتدريسها، وتعمق المعلم في دراليه تخصصه يتطلب منه أن يظل على صلة وتعق لئل

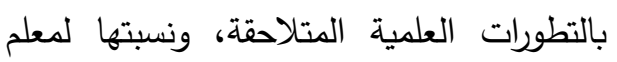
المرحلة الابتدائية .ب \% ب بينما معلم المرحلة

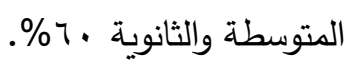
الجانب التربوي: يشمل هذا الجانب بعض

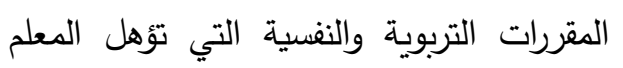

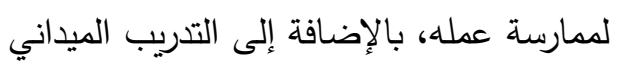

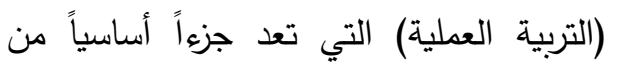

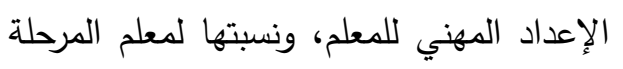

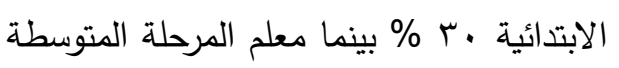

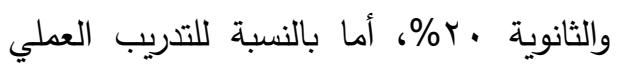

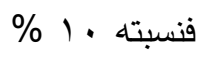
الجانب الثقافي العام: وهو يتضمن إعداد المعلم في هذا الجانب بما ينمي وعيه بثقافة مجتمعه ومشكلاته، ونسبتها لمعلم المرحلة

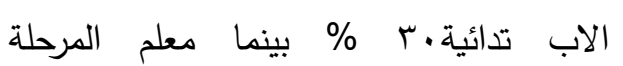

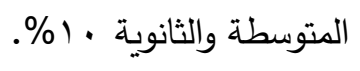
- نظم التقويم والاختبارات: تتتوع نظم التقويم التي يخضع لها الطلاب المعلمين بكليات

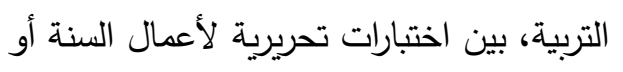

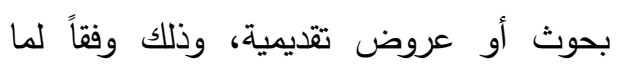
يحدده عضو هيئة التدريس، إضافةً إلى لى 
تركز برامج إعداد معلمي المرحلة الابتدائية الماجتير , وعادة ما التربية في الجامعة بغرض الإعداد المهني

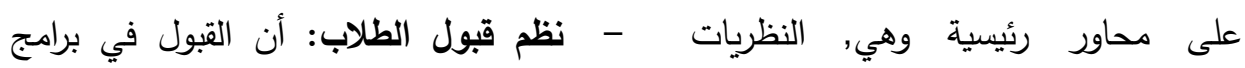

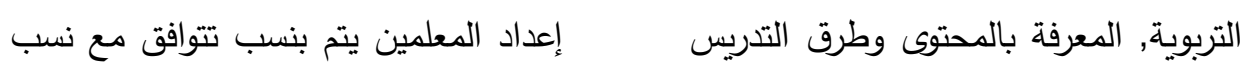

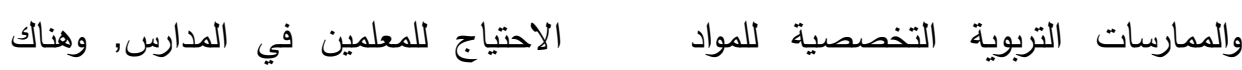
الدراسية. أما معلم المرحلة الثانوية فيشترط مرحلتين لعملية الاختيار لتأهيل المعلمين

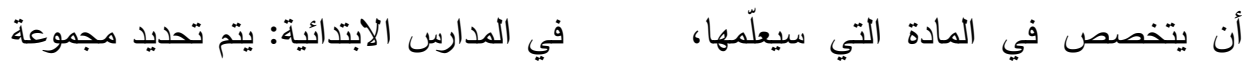

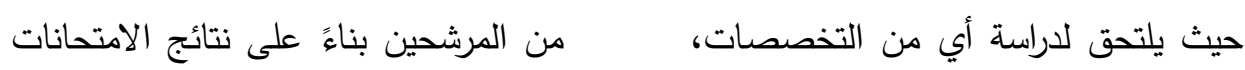

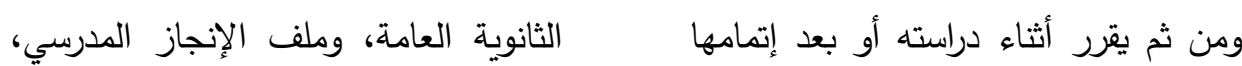

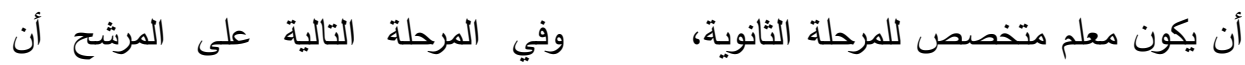

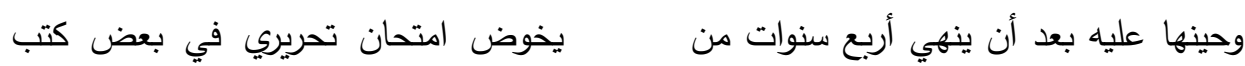

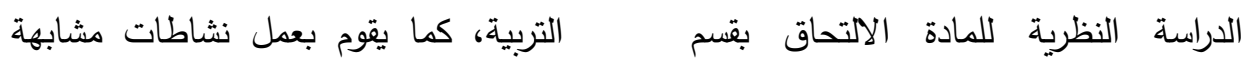
لما يحدث داخل جدران المدرسة، حيث

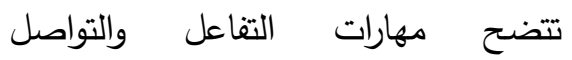
الاجتماعي لاى المرشح، بعد ذلك تجرى

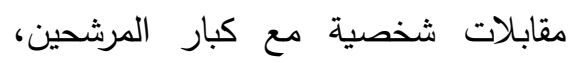
ويتم سؤالهم عن لماذا قرروا أن يصبحوا

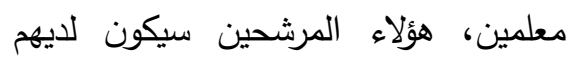
القدرة العالية لإكمال برنامج إعداد المعلمين الصارم. من الملفت في معايير القبول هو إعادئ ملاحظة مهارات التواصل لدى المرشح عبر ممارسته لنشاطات مشابهة للمدرسة، ماتهات والتي تفتقر إليها الكثير من أنظمة القبول في برامج إعداد المعلم في مختلف الدول. - - جوانب الإعداد :من البرامج التي يتم تدربسها في فنلندا: التربية في الجامعة المخصص لإعداد

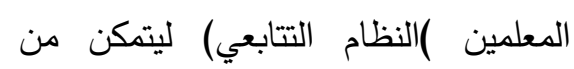

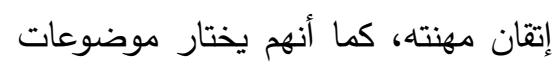
بحثية مرتبطة بمواده الدراسية التخصصية، وفي نهاية البرنامج ذي الخمس سنوات التراتية يحصل على درجة الماجستير • ومن خلال استعراض نظام إعداد المعلمين

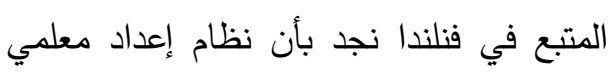
المرحلة الابتدائية هو نظام تكاملي حيث أنه يركّز على إعداد المعلم علمياً وتربوياً ومهنياً جنباً إلى جنب دون فواصل زمنية، أما بالنسبة لنظام إعداد معلّمي المرحلة الثانوية فهو نظام تتابعي حيث بمجرد إنهاء الطالب لسنوات

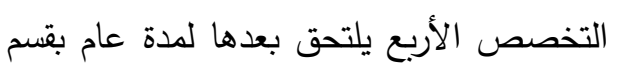




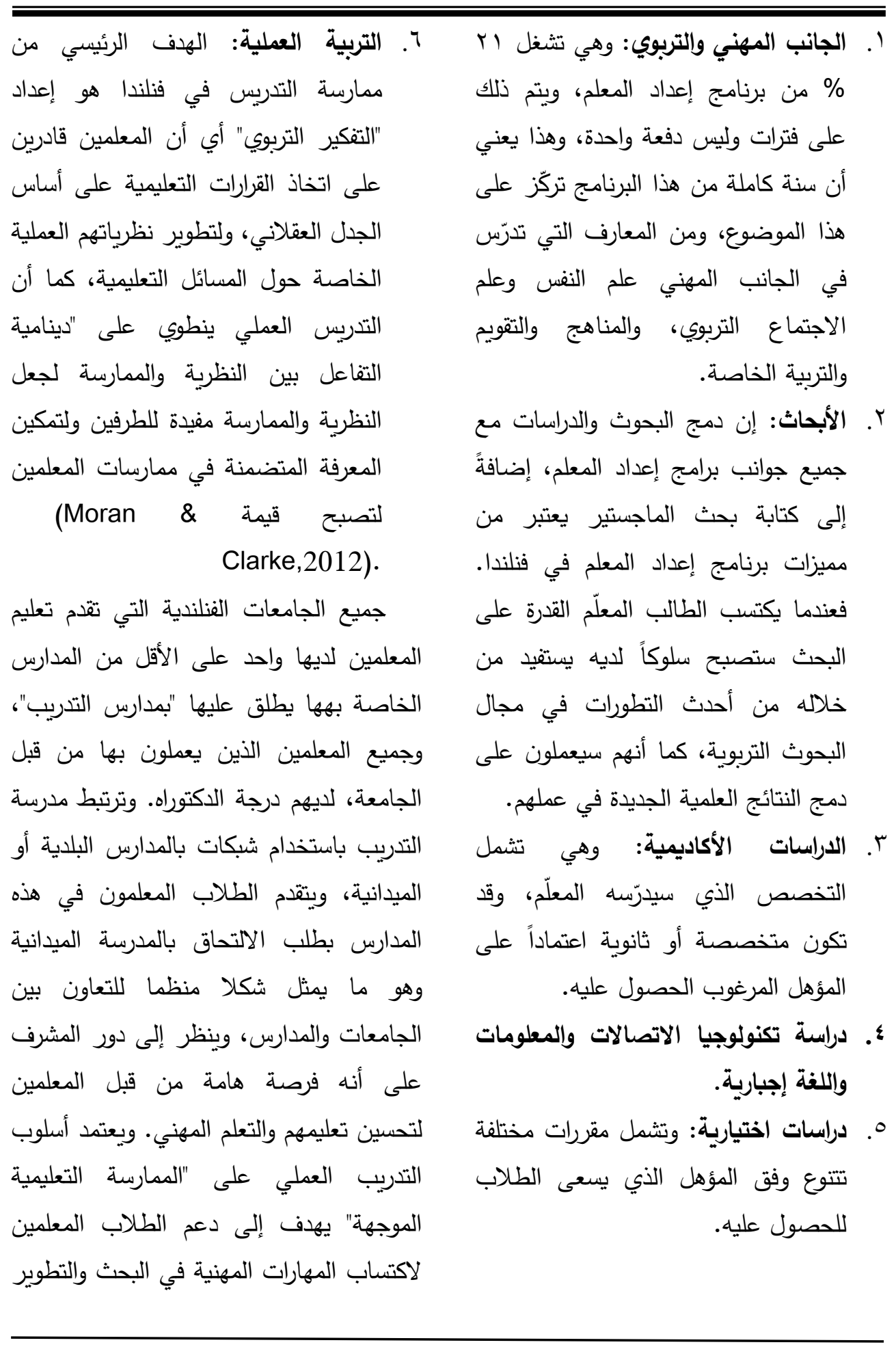




\section{يحصل على فهم أقوى للجانب الذي لديه ضعف فيه. \\ الإجابة عن السؤال الثاني: واقع برامج التنمية المهنية لمعلم القرن الحادي والعشرين في كلٍ من المملكة العربية السعودية وفنلندا. واقع برامج التنمية المهنية للمعلمين في \\ المملكة:}

تتص أحكام إعداد المعلمين في المملكة العربية السعودية على أن يفسح الدجال أمام

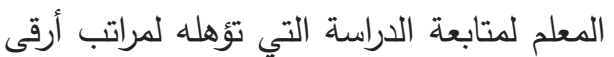

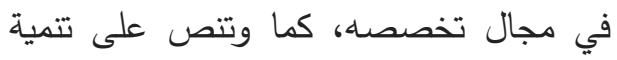
روح البحث العلمي وحب القراءة والاطلاع والمناقشة الهادفة، كما تتاولت الأحكام الخاصة ولتحة ولاعة بإعداد المعلم مرحلة ما بعد الإعداد، وأثناء ممارسة المهنة، فأشارت لضرورة تأهيل المعلم غير المؤهل، وضرورة رفع مستوى المعلم المؤهل، وتجديد معلوماته(الذبياني, ع ا • ؟). كما أن وزارة التعليم بدأت بالاهتمام بتتمية المعلم مهنياً وتحقيق أهداف التتمية المستدامة, فكان برنامج التطوير النوعي "خبرات" لتدريب

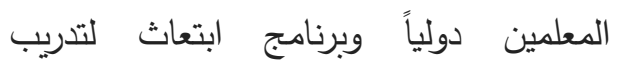
المشرفين والمشرفات في مجال stem دوبين

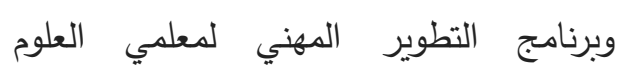
والرياضيات " تمكين" لتحسين المستوى العام لمعير لمعيدي

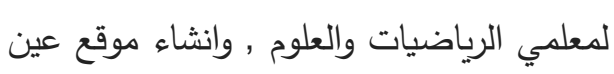
الإلكترونية والذي يدعم مفهوم التدريب عن بعد التياء

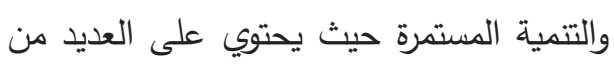

وتقييم عمليات التعليم والتعلم. الجوانب العملية قد أدمجت في العديد من مجالات الدراسة الأخرى.(Moran \& Clarke,2012) مدة التدريب العملي في مؤسسات إعداد المعلمين في فنلندا تصل إلى سبعة أسابيع خلال أربع سنوات من السنوات الخمس،

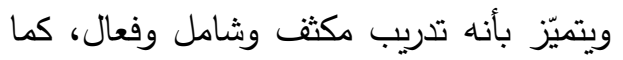
يتضمّن نظام توجيه وارشاد بالغ الدعم، يشمل تشئل

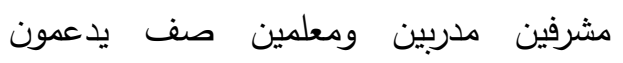
طلابهج المعلمين خارج الصف بمسناعدين

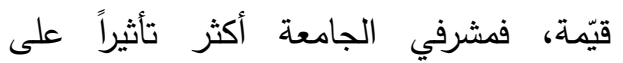

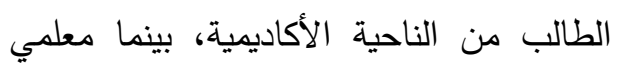

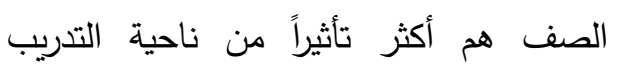
العملي، لأنهم أكثر دراية بالمناهج وطرق تائر التدريس في المدرسة، إن هذا التركيز على لانى العلاقة بين المشرفين ومعلمي الصف والطلاب المعلمين هدفه رؤية الطلاب كيف أن النظرية والتطبيق في تفاعل مستمر مع بعضها البعض. - - نظم التقويم والاختبارات: في فنلندا لا يتم إعطاء الطلاب في برامج إعداد المعلمين درجات، بل على التقويم، حيث يقدّم كتغذية راجعة مكتوبة كانت أو لفظية

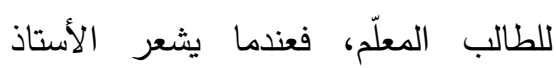
الجامعي أن هناك مواطن ضعف معيّنة

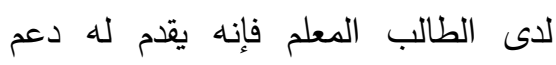

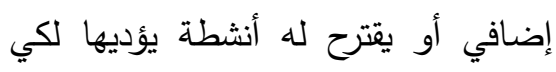


الخدمات التي تساهم بتنمية المعلم مهنياً بما المفاضلة للترقية والنقل والأداء الوظيفي

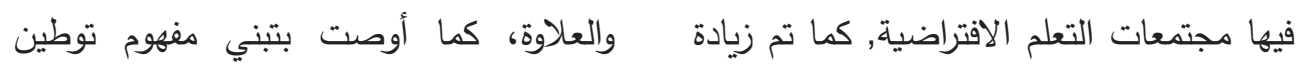

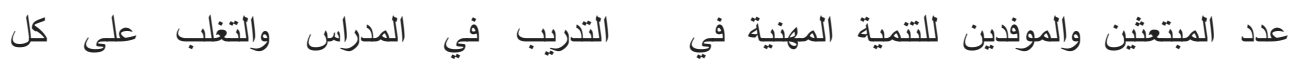

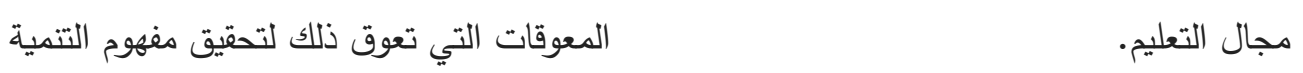

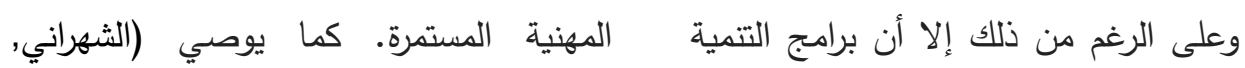

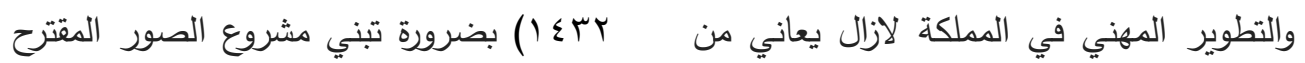

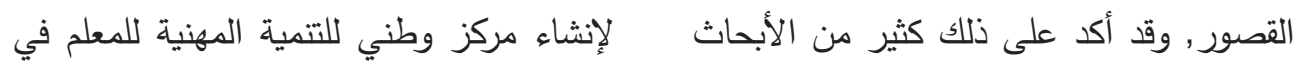

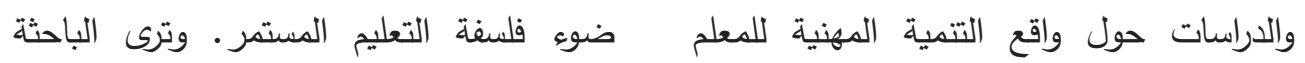

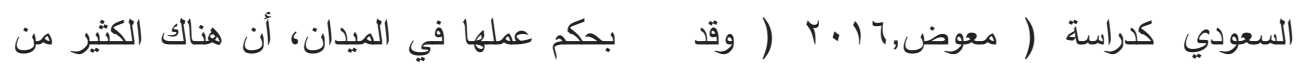
أجمعت نتائجها على القصور في جوانب المعلمين والمعلمات وجدوا فجوة بينهم وبين التتمية المهنية للمعلم في المملكة وعدم رضاهم المناهج وطرق التدريس الجديدة والطلاب؛ مما

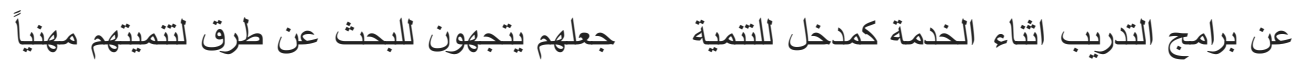

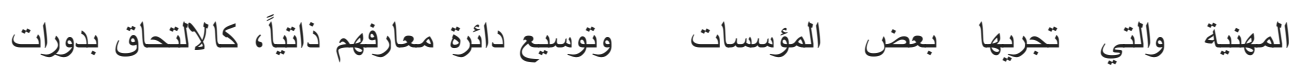
التعليمية كإدارات التدريب التربوي ومكاتب التدريب في المؤسسات المختلفة والبحث

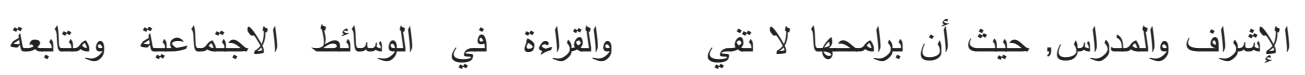
بحاجات المتدربين وأسلوبها روتيني وبعدها عن القنوات الخاصة بتطوير المهارات والممارسات

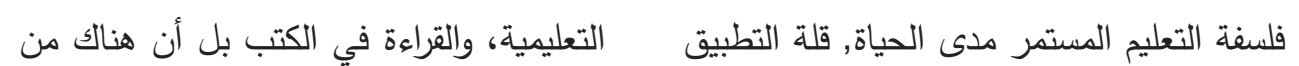

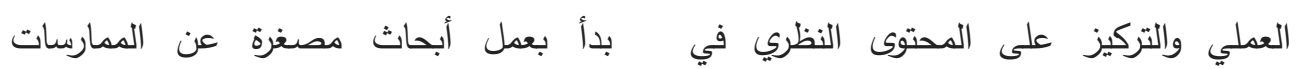
التدريب, نقص المدربين المؤهلين للتدريب, كما التعليمية الجديدة. أنها غير الزامية, وغياب المشاركة في تصميم اقع برامج التنمية المهنية للمعلمين في

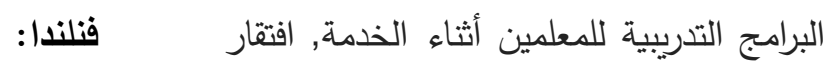

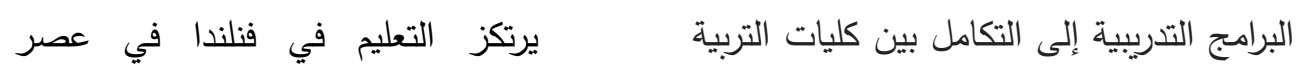

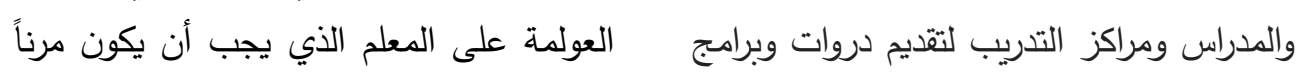

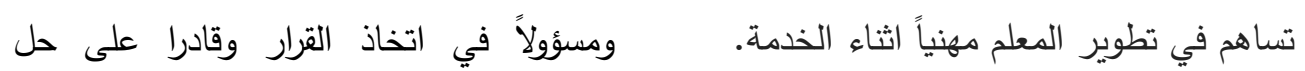
وقد أوصت كثير من الأبحاث والدراسات المشكلات بالطرق العصرية ويسلك سبل التعلم بوضع ميزات للحصول على هذا النوع من التعاوني واستخدام شبكات التواصل الاجتماعي

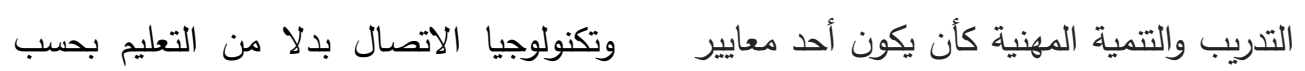


وتعتبر مشاركة المعلمين في الأعمال

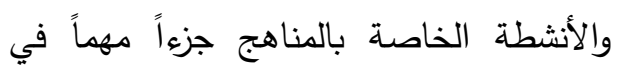
برامج التتمية المهنية للمعلمين، حيث يشارك المعلمون النشاط الوطني في عملية إعداد المناهج المحلية التي تتولاها المقاطعات. وهنالك أيضاً مناهج يتم إعدادها داخل المدارس يتولى المعلمون من خلالها مناقثة جميع الموضوعات المهمة ذات الصلة بعملهم في مني هنئ المدارس ويتخذون قرارات بشأنها، ومن خلال هذه العملية يتبادلون الأفكار والقيم والأهداف ونداف الأساسية لعملهم. وجدير بالذكر بأن عملية المناقثة والتخطيط هذه مهمة جداً لتتمية خبرات المعلمين طوال فترة ممارستهم لمهنة التدريس بشكل منهجي وتعاوني (الدخيل, $\cdot(r \cdot 10$

أوردت وزارة التربية والتعليم الفنلندية برنامجاً للتنمية المهنية للمعلمين شمل توصيات خاصة بتدريب المعلمين أثناء الخدمة في تئي الجامعات والكليات التتنية كجزء من التتمية مدى الحياة، وتعزيز دور الجامعات في تقديم سلسة من الدورات التدريبية التي تمكن المعلم

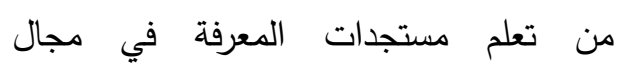
التخصص وأمور التربية، وتبادل الأفكار

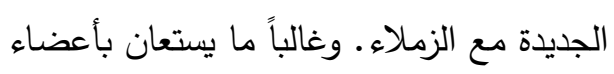

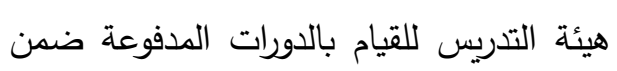
البرنامج الرسمي للتدريب والتتمية المهنية

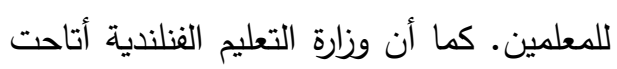

المعايير التقليدية. وكان التعلُم المستمر مدى

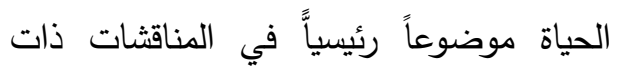
الصلة بالسياسات التعليمية، ونتيجة لذلك، فإن

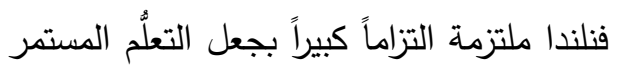
مدى الحياة (الدخيل, 10 • r). حيث يثار إلى لى

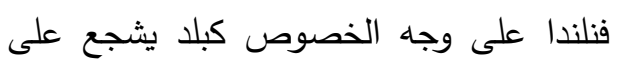
تطوير المعلمين على عدة مستويات. لذا يحظى المعلمون بتتمية مهنية الزامية،

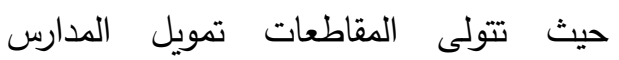
الفنلندية لأجل متطلبات التتمية المهنية؛ لذا تختلف متطلباته بحسب المقاطعة. وتطلب لاجب الحكومة الوطنية من كل مقاطعة أن تمول ثلاثة أيام على الأقل من التطوير المهني الألي الإلزامي السنوي، وتختلف المدئ المدئ الزمنية المستغرقة في التتمية المهنية على نحو كبير بين المقاطعات. ويشير (sahlperg,2010) إلى أن المعلم الفنلندي يقضي سبعة أيام في

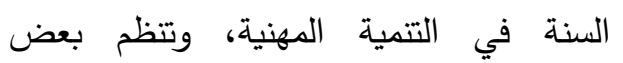
المقاطعات، ودورات وبرامج تدريبية متعددة أثناء العمل كمدخل للتتمية المهنية للمعلم، كما لتماته تنظم المدارس برامج تدرببة اثناء الخدمة حسب

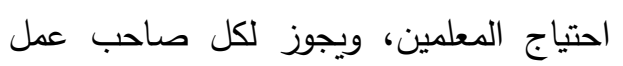
تتظيم دورات تدريبية أو الاستعانة بمزودي التعليم. وقد خصصت وزارة التربية والتعليم

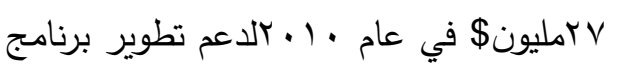

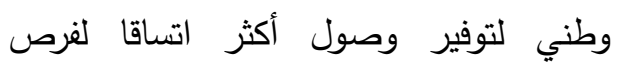
التتمية المهنية، وتأمل في مضاعفة التمويل. 


\begin{tabular}{|c|c|}
\hline \multicolumn{2}{|r|}{ لعولة } \\
\hline وخلق المعارف الجديدة، والكفاءة. كما تم انشاء & على درجة الدكتوراه كجزء من التتمية \\
\hline برامج للتدريب عن بعد من قبل الجامعات & . (Niemi \& Siljander, 2013 \\
\hline وربطها بالمدارس للتنمية المهنية للمعلمين. كما & وقد أشارت نييمي (Niemi,2015) إلى \\
\hline أن من واجبات أعضاء هيئة التدريس اثراء & أن التتمية المهنية في فنلندا تقوم على مبدأ \\
\hline بيئات التعلم الإلكترونية بمتوى للتدريد & ى الحياة والذي يبدأ في تعليم المعلم \\
\hline والتتمية المهنية. & ل إلى التقاعد، كما أن \\
\hline هذا وقد ظهرت عدة مشاريع تهدف إلى & ب فنلندا متعددة منها، الأسلوب القائم \\
\hline تتمية المعلمين مهنيا أثناء الخدمة كشروع & سة حيث أن المدارس مكلفة بتطوير \\
\hline "دائرة من الأصدقاء" في المدراس التي تضم & وتتنميه معلميها، كما تعتمد على أسلوب \\
\hline معلمين من مختلف التخصصات يدرسون نفس & التتمية القائم على مجتمعات الممارسة المهنية. \\
\hline المجموعة من التلاميذ لمشاركة المعرفة & أساليب التتمية حضور المؤتمرات، \\
\hline وملاحظة أداء بعضهم البعض، وايضاً " فريق & وإجراء البحوث، فهو الهدف الرئيسي من \\
\hline التعليم التكنولوجي" يقوم على التعاون ويضم & التعليم الأولي للمعلمين في فنلندا. \\
\hline مختلف الخبرات من المعلمين لأجل المشاركة & كما يقوم الاتجاه الجديد للتتمية المهنية \\
\hline والدعم المتبادل في هذا الفريق، فالفرق & للمعلمين في فنلندا على (1) دعم المجتمع \\
\hline التعاونية والاجتماعات التعاونية تساعد الأفراد & المدرسي (مجتمعات التعلم المهنية) لعبور \\
\hline على التعرف على بعضهم البعض والاستفادة & الحدود نحو التعاون متعدد المهنيين ليحقق \\
\hline من خبراتهم وحل المشكلات المشتركة". & التتمية المستدامة، (ץ) تصميم مجتمع \\
\hline وشروع المجتمع المدرسي (ISC) هو نموذج & المدارس المبتكرة باستخدام النهج القائم على \\
\hline شامل للبيئة المدرسية التي تدعم تعلم وتعليم & التصميح مع العديد من الشركاء، (r) ربط ما \\
\hline المهارات القرن الحادي والعشرين في المدارس & قبل الخدمة وأثناء الخدمة، (ع) تعليم المعلمين \\
\hline المحلية من خلال تطبيق التكنولوجيا الجديدة & الأسلوب القائم على البحوث في العلوم \\
\hline للتعاون. ولتعزيز التعلم الثخصي مع الهواتف & والتكنولوجيا والرياضيات(stem) ، ( () المنهج \\
\hline النقالة وربط الطلاب مع الأحياء والأماكن & القائم على المعرفة والبحث. \\
\hline ياض الأطفال والمكتبات & نهج الإبداع أيضا مها \\
\hline النة & 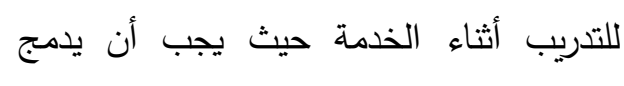 \\
\hline
\end{tabular}


الثخصية وكذلك تختلف في نوع التهات الاختبارات حيث أنها تركّز على الجوانب المعرفة التربوية وكذلك المهارات العملية ومهارات الاتصال الهامّة، كما تتميّز فنلندا بالاهتمام بالتحقق من قدرات

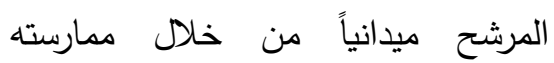
لأنشطة مشابهة لأنشطة المدرسة، وعامّة

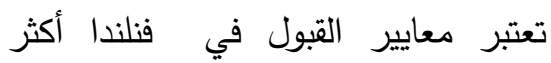

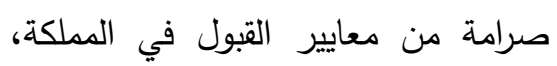
ويتّضح ذلك من خلال نسب القبول الكبيرة في المملكة مقابل النسب البسيطة في فنلندا، مما يجعل المقبولين بدولة فنلندا هم نخبة النخبة، وهذ النتيجة تثّقق

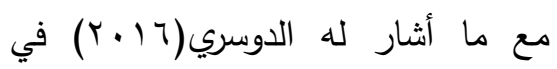
دراسته، والتي أظهرت أن معايير القبول في كليات إعداد المعلمين في السعودية لا

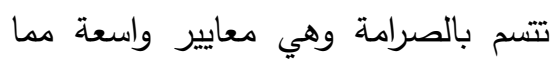
يؤثر على انقاء معلم المستقبل.

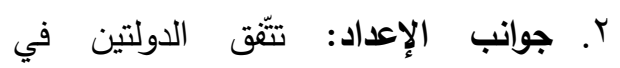
اهتمامها بالجانب الأكاديمي، والجانب التربوي، والتربية العملية، إلا أن فنلندا

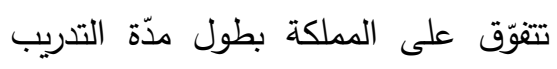

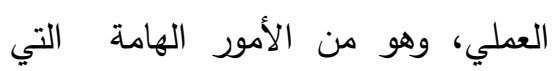
تكسب الطالب المعلم الخبرات الازمة للممارسة كما في الواقع، وهذه النتيجة

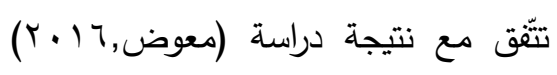

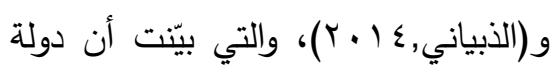

و و و كما يعمل الباحثون والباحثين من خلال عدة دورات، في محاولة لخلق ثقافة تعاونية، والقيمة الأساسية لهذا لهات التعاون هي خبرات مشتركة وباستخدام أدوات تكنولوجية (Niemi \& Siljander, 2013) الإجابة عن السؤال الثالث: ما أوجه الثبه والاختلاف بين برامج إعداد الثال المعلم وبرامج التنمية المهنية في المملكة العربية السعودية وفنلندا. من خلال عرض الثبه والاختلاف بين كل من برامج إعداد معلم القرن الحادي والعشرين وتتميته مهنياً في فنلندا والمملكة العربية السعودية، والتي تم تتاولهم بالتحليل المقارن، كما يلي: - برامج إعداد المعلم: تتّقق المملكة

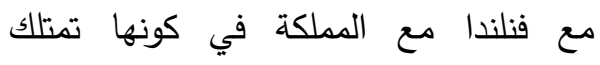
النظامين التكاملي والتتابعي في مؤسسات الإعداد. وتختلف عنها في اشتراط درجة الماجستير للمعلم الفنلندي، ومدته سنتان سواء للمرحلة الابتدائية أو الثانوية، بينما المملكة تشترط درجة البكالوريوس واختبار كفايات المعلمين لممارسة مهنة التعليم. 1. نظم القبول في برامج الإعداد: تتقق لمقارئ الدولتين في اشتراطها لإتمام المرحلة

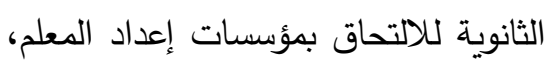
وكذلك اشتراط حسن السيرة و السلوك، واعتماد عدد من الاختبارات للالتحاق بها، إلا أن فنلندا تختلف بإجرائها للمقابلات 
وقد ألزمت الحكومة المقاطعات بدعم

التتمية المهنية للمعلم حسب احتياجه مالياً

ووضع ميزانية عالية لذلك لتحقيق مبدأ التعلم

المستمر والتعلم مدى الحياة كما تعدد أساليب

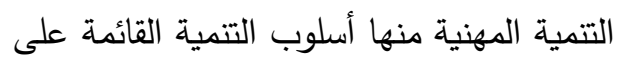

المدرسة والمجتمعات المهنية والبحوث وحضور

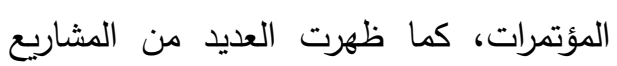

لدعم تتمية المعلمين مهنياً كمشروع فريق التعلم

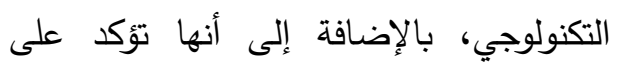

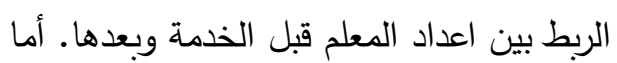

المملكة فقد حرصت الوزارة على تتمية المعلم

مهنياً أثناء الخدمة وبدأت بمشاريع التوطين

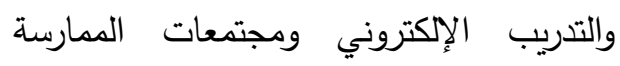

المهنية، إلا أنها مازالت تعاني من القصوري من من

حيث التدريب الإلزامي المناسب لاحتياجات

المعلمين لتطوير أنفسهم وتتميتها مهنياً.

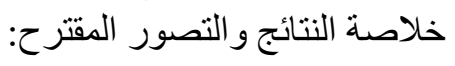

إن إعداد المعلم عملية مستمرة تشمل

الإعداد قبل الخدمة إعداداً جيداً والتدريب أثناء

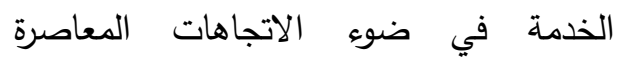

وكفايات القرن الحادي والعشرين.

وتوصل البحث إلى عدد من النتائج أهمها:

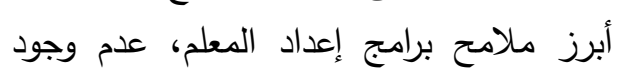

معايير مقننة يتم من خلالها انتقاء المعلمين.

التحاق أعداد كبيرة من غير المؤهلين تربوياً

للعمل في التدريس. التفاوت في المكونات

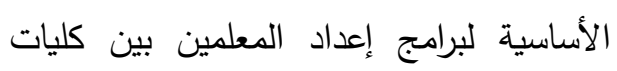
التربية في الجامعات السعودية. تقادم خطط لادئ لين
المقارنة تهتّم بربط التعليم النظري بالتعلم

العملي، ممّا يجعل التعليم ذا أثز فعّال

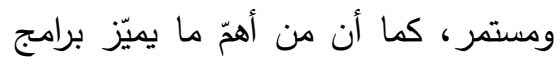

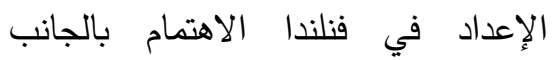

البحثي، وهذا أمر هام جداً، لبناء معرفته لإعداد

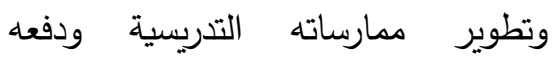

للاستفادة من آخر المستجدّات ، وهذا ما

تفتقر إليه برامج الإعداد في المملكة.

r. نظم التقويم والاختبارات: تختلف المملكة

مع فنلندا في نظام التقويم في مؤسسات إعداد المعلم، حيث تعتمد المملكة على لفى فئل فونسات عدد من وسائل التقويم وأهمها الاختبارات التحريرية بشكل رئيس، بينما في الجانب الآخر نجد فنلندا قد اتّبعت نظاماً خاصاً بها وهو التقويم المستمر، وقد يكون نظام

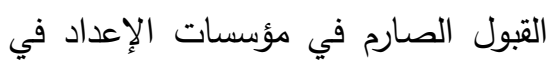
فنلندا له الدور الأكبر في هذه الثقة في مؤنيات الإعاد في

$$
\text { قدرات الطلاب. }
$$

\section{-برامج التنمية المهنية لمعلم:}

تميّزت الخبرة الفنلندية بتركيزها على تتمية

مهارات التعلم الذاتي لدى المعلم، حيث سعت لهت

لتخريج معلم يعمل على تطوير ذاته، ويعتمد ـ

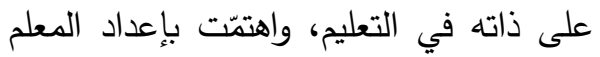

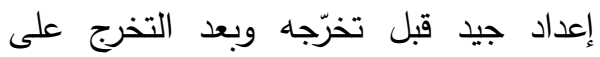
التعلم مدى الحياة كشرط للاستمرار بالمهنة. كما أن التتمية المهنية الزامية على كل معلم لمدة لا تقل عن ثلاث ايام بالسنة. 
الحصول عليه لمزاولة المهنة. فترة الدراسة تقريبا ه سنوات. المناهج تجمع بين النظرية والتطبيق. برامج التتمية متتوعة وتعتمد بأغلبيها على الأساليب الحديثة كالتتمية المهنية القائمة

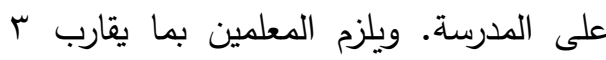
أيام في السنة للالتحاق ببرامج التدريب قابل

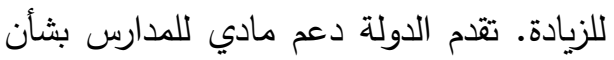

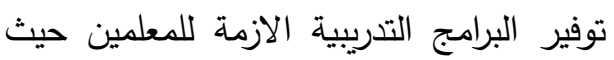
أنها تشجع التطوير والتتمية. التصور المقترح: بناء على أدبيات البحث والدراسات السابقة والإجابة على أسئلة البحث تم وضع التصور المقترح التالي: - الاجها

1. الأسس والمنطلقات التي اعتمد

عليها التصور المقترح: أرتكز التصور المقترح على عدد من الأسس والمنطلقات في بنائه

$$
\text { على النحو التالي: على التئ }
$$

أهداف وسياسة التعليم في المملكة

العربية السعودية، واقع إعداد وتتمية المعلم في

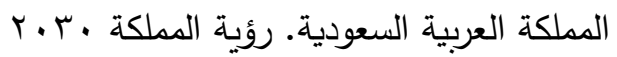
لتطوير مهنة التعليم. التجارب العالمية الناجحة في مجال إعداد وتطوير المعلم في فنلندا. التغيير المستمر في أدوار المعلم استجابة للتطور التقني والمعرفي. تتمية المعلمين ممن التمان هم على رأس العمل في المجال التربوي

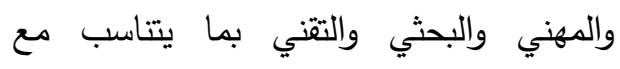

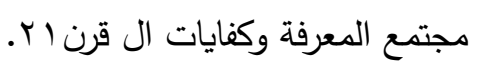
r. أهداف التصور المقترح
وبرامج الإعداد. التركيز على الجوانب النظرية والمعرفة وإهمال الجوانب التطبيقية. الانفصال بين برامج إعداد المعلم قبل الخدمة وتدريب

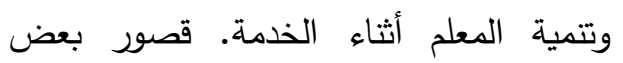
البرامج عن تزويد الطالب المعلم بأهم كفايات ومهارات ال قرن آب.ضعف مخرجات كليات التربية. القصور في برامج التربية الميدانية والإشراف عليها. الفصل بين برامج إعداد المعلم قبل الخدمة وتتميته أثثاء الخدمة. - - أبرز الملامح التي تواجه تتمية المعلمين

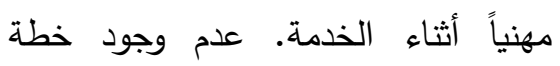
واضحة شاملة لتدربب وتتمية المعلمين مهنياً. ضعف الاهتمام بالجانب التطبيقي

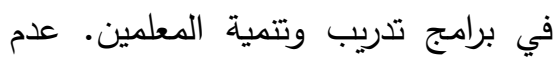

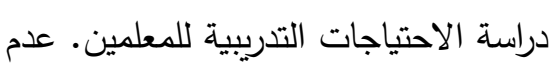
تتوع أساليب التمية المهنية حيث أن الن التئين الأسلوب الغالب هو الأسلوب التقليدي. عدم إلزام المعلمين وربط ذلك بالحوافز الغاب البط المادية والمعنوية. ضعف الدمام الدعم المادين وريط داليط للمؤسسات المشرفة على برامج التتمية. ضعف دور الجامعات في تقديم برامج

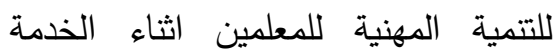
لتحديث معارفهم في مجال التخصص. - أبرز الملامح التجربة الفنلندية في برامج فئمان الإعداد والتتمية المهنية معايير القبول صارمة وشديدة لانتقاء أفضل العناصر من المعلمين المستقبلين، تعد درجة الماجستير مطلب واجب لاجب لاءن 


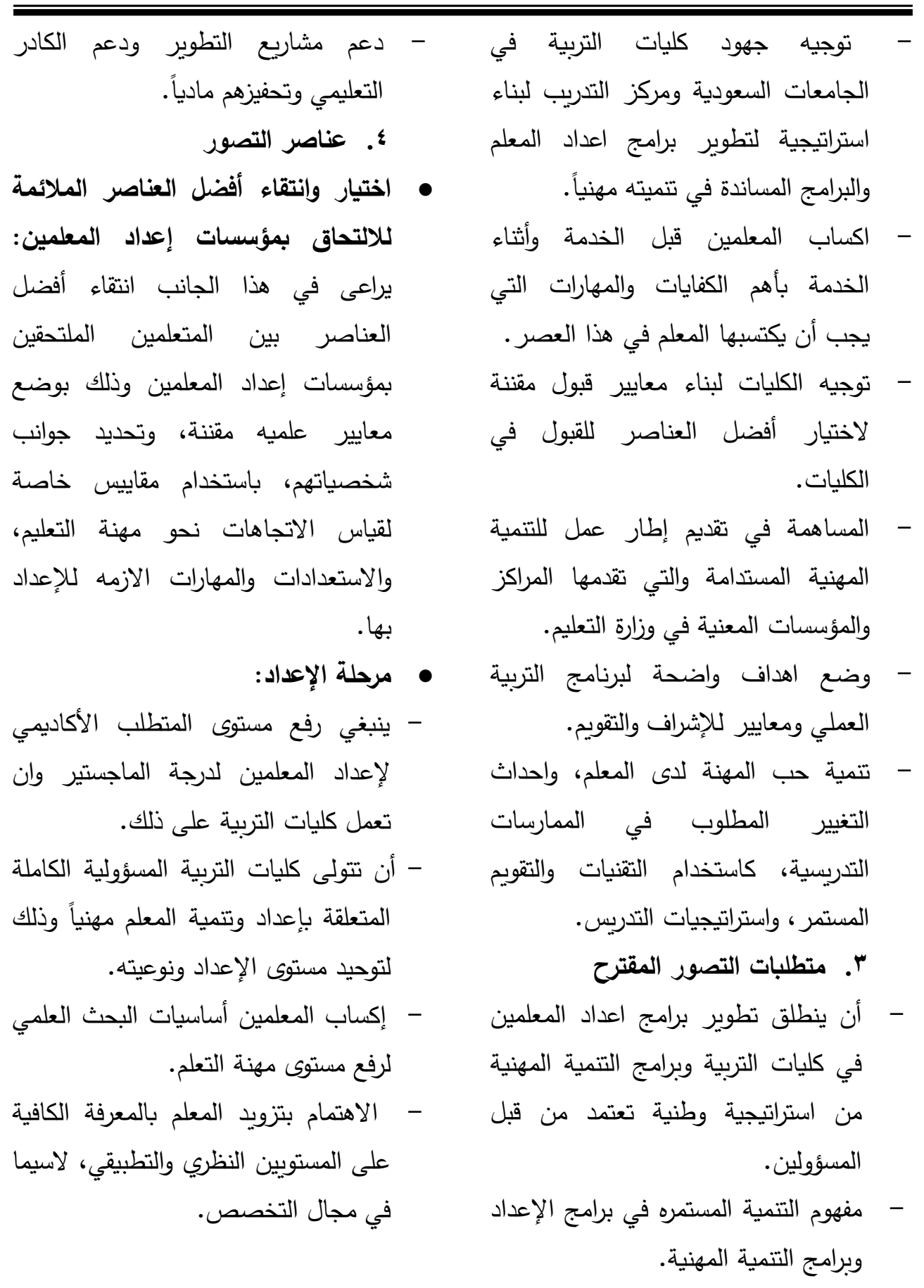




\begin{tabular}{|c|c|}
\hline - دمج التقنية ووسائل التقنية الحديثة بمناهج المعلمين (كاستخدام الفيديو والصور & - زيادة الوقت المخصص للتزبية العملية، \\
\hline والصوت وبرامج العروض التقديمية & 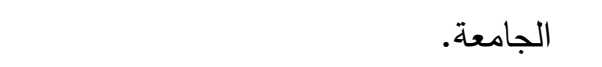 \\
\hline مثلPrize وبرامج انثاء النصوص مثل & - يطبق التربية العملي في مدارس تشرف \\
\hline المختلفة) للمناقثة والحصول على التغذية & - اكساب الطلاب المعلمين الممارسات \\
\hline الراجعة ولعمل المشاريع، ويتضمن ذلك & التدريسية الجيدة بحيث يتم تتفيذ أحدث \\
\hline فهم القضايا الأخلاقية عند الاستخدام. & استراتيجيات التدريس، ومهارات التخطيط \\
\hline - أن تتبع الكليات النظام التكاملي بين مواد & للدروس ومهارات التقويم، ومهارات \\
\hline التخصرفة والمواد التربوية لتكامل & كالتقنيات الحديثة مفتوحة التقنيات التعليمية المختلفة، \\
\hline - أن يتم الاهتمام بالجانب الثقافي بحيث يتم اللغة العربية والإنجليزية والدين & التعلم والتعليم. التوسائط الاجتماعية المختلفة في \\
\hline والمنهج العالمي والمواطنة والوعي البيئي. & - إعادة النظر في برامج إعداد المعلمين \\
\hline • التنمية المهنية: إن التربية عملية مستمرة & لتواكب الاتجاهات الحديثة في الإعداد \\
\hline ومن الضروري استمرار عملية التتمية & والتتمية المهنية القائمة على مهارات القرن \\
\hline المهنية للمعلم طيل فترة عمله الوظيفي، & الحادي والعشرين في ظل الثورة المعرفية، \\
\hline ومن أكبر مشكلات التعليم في المملكة & حيث تتضمن المهارات العليا للتفكير، \\
\hline العربية السعودية غياب خطط التتمية & إدارة المهارات الحياتية، إدارة قدرات \\
\hline المهنية المتكاملة وتكاملها مع برامج، & المتعلمين، إدارة فن التعليم، إدارة منظومة \\
\hline 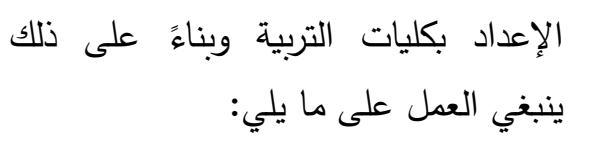 & والتقيم الأخلاقية، التتخدام المهارات الثخية الذاتية، تحليل \\
\hline - العمل على دراسة حاجات المعلمين & وتقييم الأدلة والحجج والمطالبات \\
\hline في ضوغباتهم، ووضع خطط التتمية المهنية & والمعتقدات بفعالية، والمواطنة العالمية \\
\hline - تكليف كليات التربية بعقد دورات تدريبية & المهنة. \\
\hline
\end{tabular}


- عدم التكامل بين برامج الإعداد وبرامج التمية المهنية، حيث لابد من التكامل بين

$$
\text { هذه البرامج. }
$$

- ضعف البنية التحتية والإعدادات المختلفة في مؤسسات الإعداد والتتمية المهنية، حيث لابد من تطوير البنى التحتية لتؤدي

$$
\text { هذه المؤسسات الغرض منها. }
$$

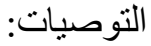

وانطلاقا من العرض السابق نقدم عدد من

$$
\text { التوصيات التالية: }
$$

- أن تتبنى وزارة التعليم التصور المقترح لتطوير برامج كليات التربية وبرامج التتمية المهنية للمعلمين. - الاستفادة من الاتجاهات العالمية في البلاد المتطورة في مجال إعداد وتتمية المعلم والاستفادة منها بما يتناسب مع ظروف إمكانيات التعليم لدينا. - التكامل بين برامج إعداد وتدريب المعلم،

$$
\text { لتوحيد الأهداف. }
$$

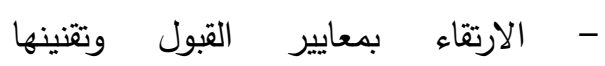

$$
\text { لاستقطاب أفضل العناصر • }
$$

- تطوير مهارات المعلمين البحثية وطرق التعلم الذاتي، الاهتمام ببرامج التتمية المهنية للمعلمين. المراجع اجعَ: العربية
لتمية المعلمين مهنياً اثناء الخدمة، ونشر محتوى التدريب عبر مواقع التعلم

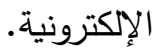
- أن يتم استخدام التقنية الحديثة في جميع برامج التنمية المهنية. - يجب العمل على أساليب تتمية مهنية حديثة مثل التدريب المدرسي(التوطين)، ومجتمعات التعلم المهنية، والتدريب عن من الت الت بعد عبر شبكات خاصة تربط المدراس بالمراكز الخاصة بالتدريب. - توفير الامكانات اللزمة لتمية المعلمين مهنيًا، مثل البنية التحتية والقاعات

$$
\text { والميزانيات الكافية. }
$$

- الجمع بين النظرية والتطبيق في برامج التمية المهنية للمعلمين، وإلزام جميع المعلمين بمتابعة التمية المستمرة؛ لتحقيق

$$
\text { مبدأ التعلم مدى الحياة. }
$$

- الاستفادة من الخبرات العالمية في مجال مبال تتمية المعلمين مهنياً. ○. المعوقات المحتمل أن تواجه تطبيق

$$
\text { التصور }
$$

- عدم وضوح الرؤيسة دن قبل الوزارة تجاه التمية المهنية، حيث لابد وضع رؤية واضحة وشاملة للتمية المهنية من قبل الوزارة توضع في ضوء اهتمامات المعلمين وحاجاتهم. 


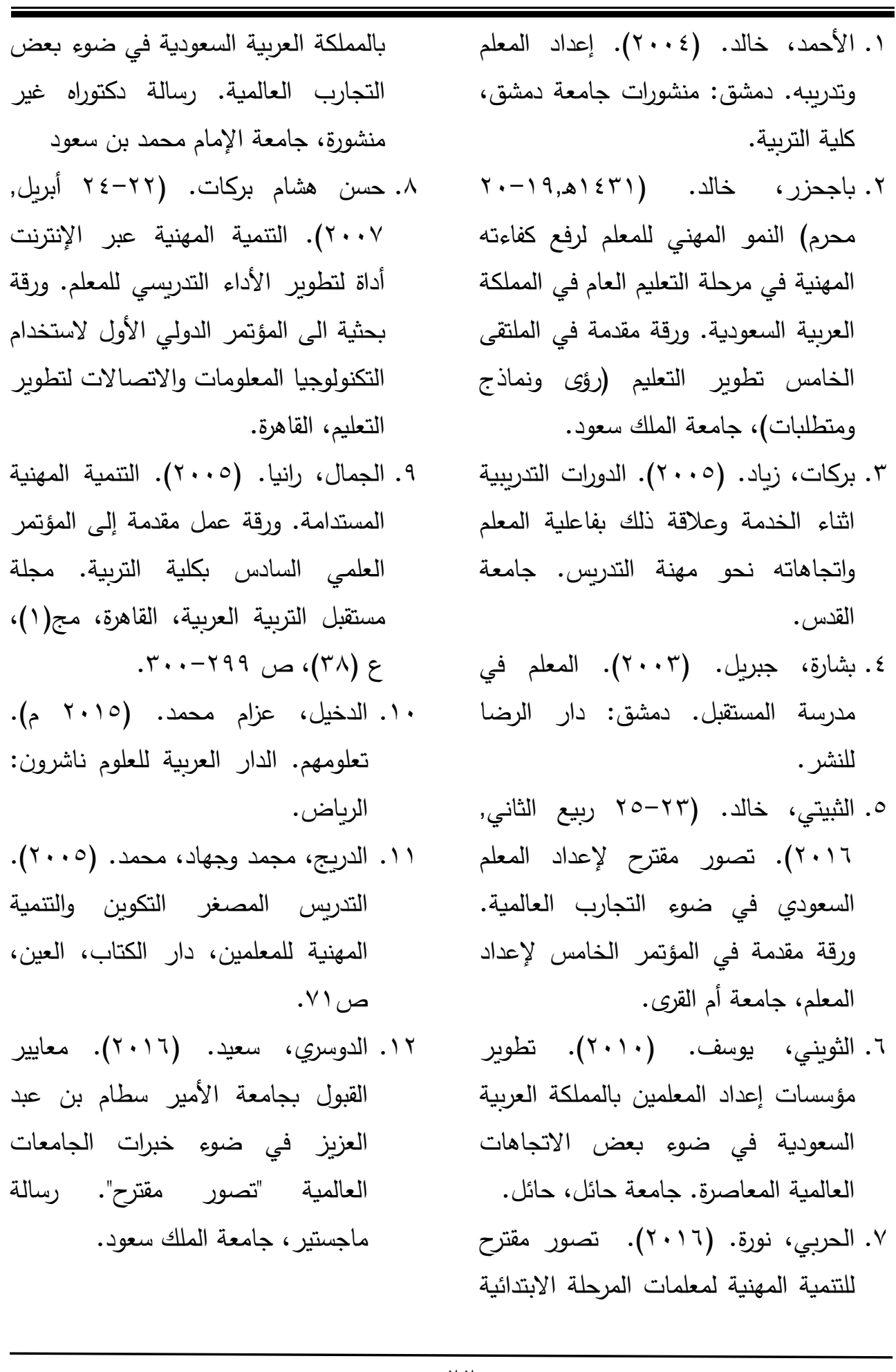




\begin{tabular}{|c|c|}
\hline 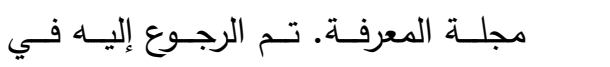 & الذبياني، منى. (ع ا • ץ). تجارب بعض \\
\hline $24 / 4 / 2017$ & الدول في إعداد المعلم وتتميته مهنيا \\
\hline http://www.almarefh.net/show & وإمكانية الإفادة منها في المملكة العربية \\
\hline content_sub.php?CUV=400\& & السعودية. مجلة كلية التربية في \\
\hline SubModel $=138 \& \mid \mathrm{I}=1682$ & 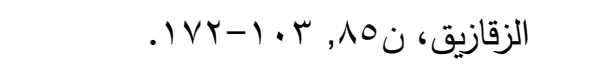 \\
\hline 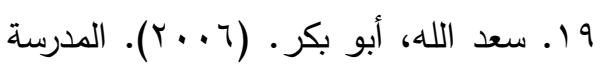 & 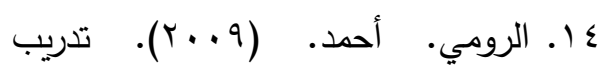 \\
\hline الفنلندية النموذج العالمي. رسالة التربية؛ & معلمي المرحلة الثانوية اثثاء الخدمة \\
\hline . $1 \leqslant r-r \leqslant, 1 r r \varepsilon$ & بالمملكة العربية السعودية في ضوء \\
\hline 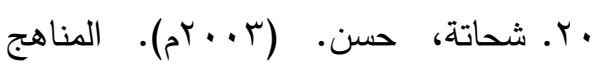 & بعض التغيرات العالمية المعاصرة " \\
\hline الدراسية بين النظرية والتطبيق. القاهرة: & تصور مقترح". دراسة دكتوراه. جامعة \\
\hline المكتبة العربية للكتاب. & الإمام محمد بن سعود. \\
\hline 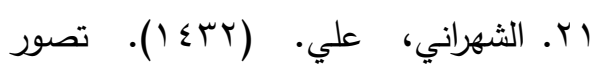 & 1. الريس، سعود. (ד 1 •r, rץ-0r ربيع \\
\hline مقترح لإنشاء مركز وطني للتنمية & الثاني). المعلم في المدارس السعودية. \\
\hline المهنية للمعلمين في المملكة العربية & ورقة مقدمة في المؤتمر الخامس لإعداد \\
\hline السعودية في ضوء فلسفة التعليم & المعلم، جامعة أم القرى. \\
\hline المستمر · رسالة دكتوراه غير منشور، & 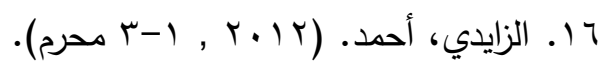 \\
\hline جامعة الملك سعود. ج & تصور مقترح لمعلم التعليم العام في \\
\hline 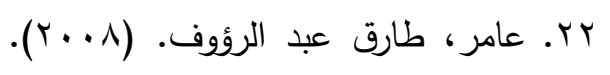 & القرن الحادي والعشرون في ظل \\
\hline اعداد معلم المستقبل. الجيزة، الدار & تحديات العولمة والتتافسية الاقتصادية \\
\hline 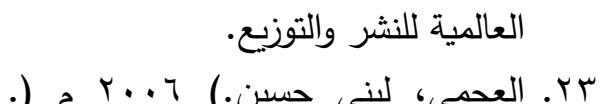 & والثقافية. المؤتمر الرابع لإعداد المعلم، \\
\hline سيناريوهات بديلة لتطوير كليات & \\
\hline ومؤسسات إعداد المعلم بالمملكة العربية & VI. الزكي، احمد عبد الفتاح). ع.... م \\
\hline السعودية حتى عام • r · rم. بحث مقدم & (التربية المقارنة ونظم التعليم دراسة \\
\hline للمؤتمر الدولي العلمي السابع بكلية & منهجية ونماذج تطبيقية. الإسكندرية، \\
\hline التربية جامعة الفيوم، الفيوم، مصر . & مصر : دار الوفاء لدنيا الطباعة والنشر • \\
\hline 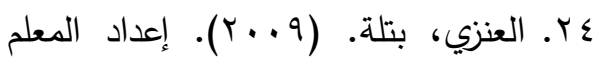 & 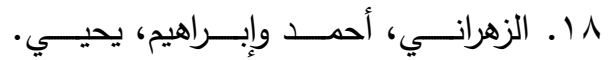 \\
\hline في دول الكتاب، الأردن العربي نماذج مقترحة. & 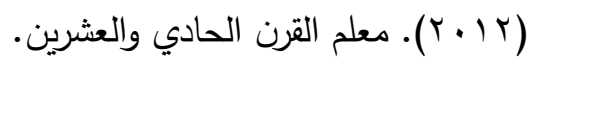 \\
\hline
\end{tabular}




\begin{tabular}{|c|c|}
\hline وعلى التربية، جامعة المعرفة: الفرص والتحديات كلية & 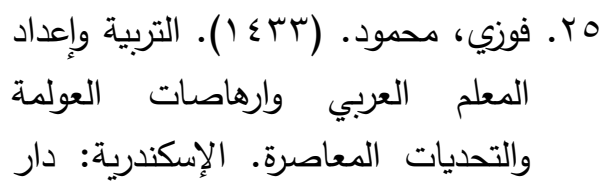 \\
\hline http://tic.kku.edu.sa/content/129 & 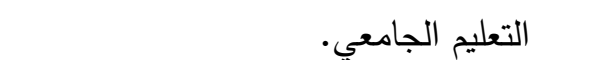 \\
\hline 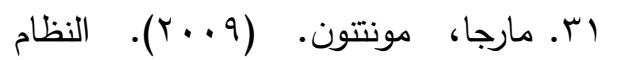 & 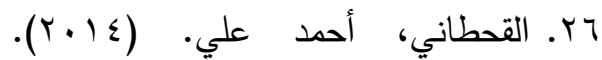 \\
\hline التعليمي الفنلندي. رسالة التربية، سلطنة & التتمية المهنية لمعلمي المرحلة الثانوية \\
\hline عمان، ع ع r, $10 \mathrm{~V}$ & بمدينة بيشة في ضوء متطلبات الجودة \\
\hline 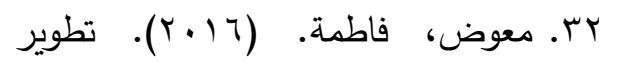 & الثاملة. رسالة ماجستير ، جامعة الملك \\
\hline برامج إعداد المعلم بالمملكة العربية & سعود. \\
\hline السعودية في ضوء المتغيرات المجتمعية & 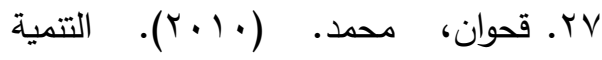 \\
\hline ومعايير الاعتماد العالمية. ورقة مقدمة & المهنية لمعلمي التعليم الثانوي العام في \\
\hline في المؤتمر الخامس لإعداد المعلم، & ضوء معايير الجودة الثاملة. الطبعة \\
\hline جامعة أم القرى. & الأولى، عمان، دار غيداء للنشر \\
\hline 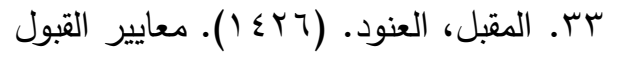 & 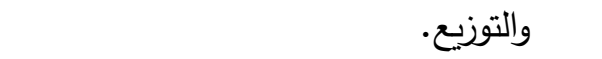 \\
\hline في جامعات المملكة العربية السعودية & 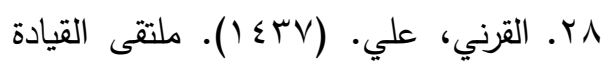 \\
\hline دراسة تحليلية وتصور مقترح. رسالة & والتخطيط التربوي الثالث. مدونة الريادة \\
\hline ماجستير غير منشورة، جامعة الإمام & الأكاديمية. تم الرجوع إليهفي \\
\hline محمد بين سعود. & http://dr-r. $\mid \mathrm{V} / \varepsilon / r \varepsilon$ \\
\hline ـ ז. المفرج، بدرية؛ والمطيري، عفاف؛ & alameri.com \\
\hline 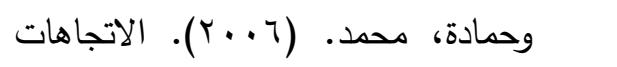 & 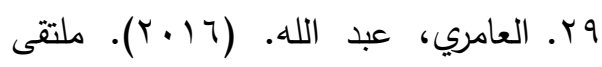 \\
\hline المعاصرة في إعداد المعلم وتتميته & القيادة والتخطيط التربوي الثالث. مدونة \\
\hline مهنياً. إدارة البحوث، وزارة التربية، & الريادة الأكاديمية. تم الرجوع إليه في \\
\hline الكويت. الكيت & http://dr-r. IV/ $/ \varepsilon / r \varepsilon$ \\
\hline هـ. المنيع، منيع عبدالعزيز · (اس؟ (هـ). & alameri.com \\
\hline برنامج اعداد المعلم بين الجمود & 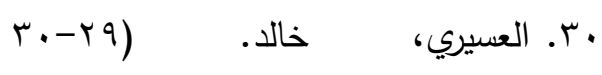 \\
\hline والتطوير · ورقة مقدة في الملتقى & 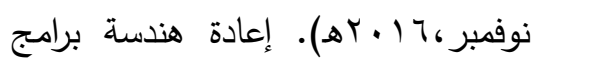 \\
\hline الخامس تطوير التعليم (رؤى ونماذج & كليات التربية بالجامعات السعودية \\
\hline ومتطلبات)، جامعة الملك سعود. & لإعداد معلم المستقبل في ضوء برنامج \\
\hline 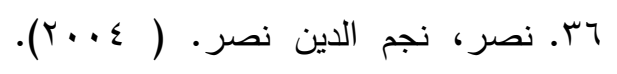 & التحول الوطني (أنموذج مقترح لوزارة \\
\hline (التتمية المهنية المستدامة للمعلمين أثناء & التعليم بالمملكة العربية السعودية). ورقة \\
\hline الخدمة في مواجهة تحديات العولمة. & علمية مقدمة في المؤتمر الدولي المعلم \\
\hline
\end{tabular}


40. Learning Curve. (2012). Lessons in Country Performance in Education. On

file:///C:/Users/TOSHIBA/Downloads 130524_Learning-curve-2012.pdf

41. Poole, Cyndi Mottola and Russell, William. (2015). Educating for Global Perspectives: A Study of Teacher Preparation Programs. Journal of Education $\bullet \mathrm{V} 195 \cdot \mathrm{N} 3$.

42. Sahlbarg, p. (2010) the Secret of Finland' S Success: Educating Teacher. Stanford Center for Opportunity Policy in Education. On http://edpolicy.stanford.edu

43. Shelbie D. Wittea, Melissa R. Grossb \& Don L. Latham, Jr.b. (2015). Mapping 21st century skills: Investigating the curriculum preparing teachers and librarians. Education for Information 31 (2014/2015) 209-225 209.

44. Niemi, H... (2015). Teacher Professional Development in Finland: Towards a More Holistic, (Finland). Psychology, Society, \& Education, Vol. 7(3), pp. 279-294 ISSN 21712085.

45. Niemi, H. , Siljander, A. M. \& the group for developing mentoring. (2013). New teachers Mentoring. Towards students' and teachers wellbeing through mentoring (in Finnish). Palmenia Centre for Continuing Education. University of Helsinki

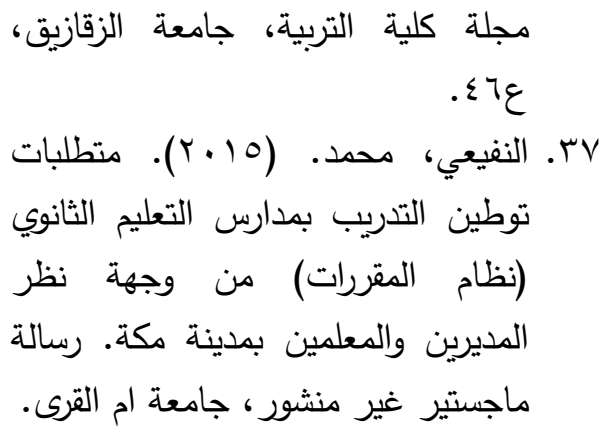

$$
\text { المر اجع الأجنبية }
$$

38. Anne M. A. \& Clarke, L. (2012). Back to the future: do lessons from Finland point the way to a return to model schools for Northern Ireland? .European Journal of Teacher Education Vol. 35, No. 3, August 2012, 275-288

39. Jutarat V., Jyrki L., Sornnate A. \& Chanita R. (2015). Ready Contents or Future Skills? A Comparative Study of Teacher Education in Thailand and Finland. Journal of Education and Learning; Vol. 4, No. 4. 